Portland State University

PDXScholar

6-1-1967

\title{
Medical-social needs in a sample population of elderly post-hospital patients
}

\author{
Rose N. Cooper \\ Portland State University \\ JoAnn G. Doyle \\ Marie N. Greyerbiehl \\ Guy H. Hancock \\ Marvin E. Husebye
}

See next page for additional authors

Follow this and additional works at: https://pdxscholar.library.pdx.edu/open_access_etds Let us know how access to this document benefits you.

\section{Recommended Citation}

Cooper, Rose N.; Doyle, JoAnn G.; Greyerbiehl, Marie N.; Hancock, Guy H.; Husebye, Marvin E.; McCoy, Gladys; McWhirter, Josephine; and Orvedahl, David H., "Medical-social needs in a sample population of elderly post-hospital patients" (1967). Dissertations and Theses. Paper 348.

https://doi.org/10.15760/etd.348

This Thesis is brought to you for free and open access. It has been accepted for inclusion in Dissertations and Theses by an authorized administrator of PDXScholar. Please contact us if we can make this document more accessible: pdxscholar@pdx.edu. 


\section{Author}

Rose N. Cooper, JoAnn G. Doyle, Marie N. Greyerbiehl, Guy H. Hancock, Marvin E. Husebye, Gladys McCoy, Josephine McWhirter, and David H. Orvedahl 


\section{AN ABSTRACT OF: THE THESIS OF}

$\frac{\text { ROSE N. COOPER et al. for the } \frac{\text { MASTER }}{\text { (Name) }} \text { in SOCIAL WORK }}{\text { (Major) }}$

Date thesis is presented

March.16, 1967

Title MEDICAL-SOCIAL NEEDS IN A SAMPLE POPULATION

OF ELDERLY POST-HOSPITAL PATIENTS

Abstract approved

$$
\text { (Major professor) }
$$

The EPP Project was a descriptive and inferential study designed to determine the psychosocial and medical needs of elderly post-hospital dischargees.

The areas of need assessed were (1) living arrangements, (2) use of leisure time, (3) vocational adjustment, (4) financial functioning and (5) adjustment to illness.

The instrument adopted for the purpose of this study was an adaptation of a schedule used in the New YorkStudy. The New York Study, described in The Elderly Ambulatory Patient: Nursing and Psychosocial Needs by Doris Schwartz, Barbara Henley and Leonard Zeitz was a long-range study of the needs of elderly clinic patients. The schedule utilized both open-end and structured responses. Interviews were conducted in the homes of respondents. 
A sample of 63 patients was drawn and found from a population of elderly dischargees of the Kaiser Foundation Hospital in Portland, Oregon. The study group was composed of 20 patients adjudged by their physicians as having a high probability of need for post-hospital skilled nursing care. The control group included 43 patients systematically selected from a sample of the general hospital populace of elderly patients discharged during the same period of time as the study group and not considered to be in need of special nursing services.

Findings yielded evidence to support the hypothes is that patients adjudged by the doctors as having more medical needs also had more social needs. A second hypothesis stating that medical and social needs of the study group were the same as medical and social needs of the control group was rejected. Those in the study group evidenced greater medical and related social needs. The third hypothesis sought to test the reliability of the Greenlick prediction formula, an instrument used in a previous Kaiser Hospital study to estimate the need for skilled nursing service in a population following hospital discharge. Findings indicated that the Greenlick prediction formula was effective in ascertaining need for immediate post-hospital care and was effective, with greater variance, in predicting needs over time. The final hypothesis as serted that the needs of the patients in the EPP Project were the 
same as those determined in the New York Study. This hypothesis was rejected when analysis of data yielded evidence that the patients in the EPP Project functioned at a higher level in all areas considered than did the patients in the New York Study.

Unexpectedly, the findings disproved the stereotype emphasized in social work literature characterizing the elderly as being needy and in distress both socially and medically. On the contrary, findings indicated that such unqualified generalizations about elderly patients as a homogeneous group cannot appropriately be made.

Collection and analysis of the data pointed to the need for social work services in the area of budgeting for medical expenses and utilization of appropriate community resources. A further indication was the need for volunteers to provide services such as transportation to enhance participation in social and recreational activities. The use of volunteers would also facilitate grocery shopping and obtaining medical attention.

Implications for further research suggested the need for additional empirical studies of elderly post-hospital patients in a variety of settings. 


\section{A PPROVED:}

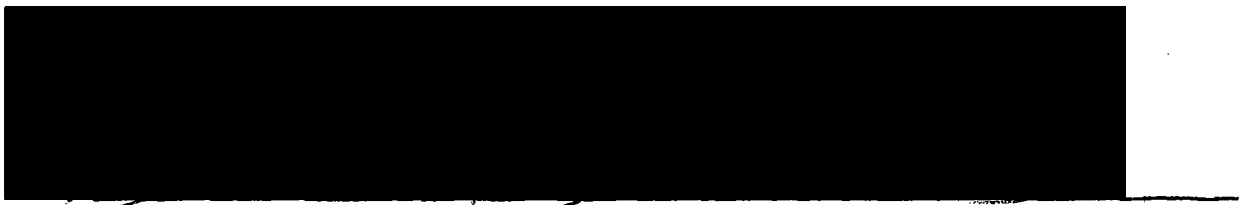

Associate Professor of Social Work

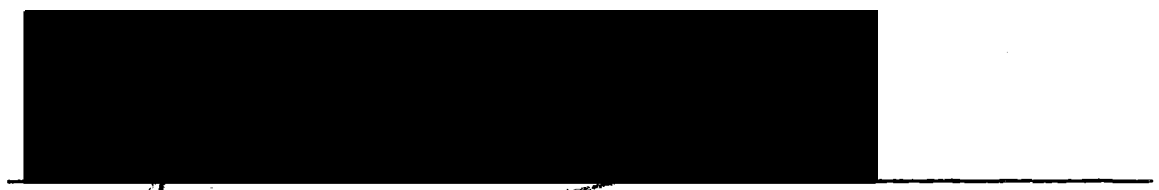

Dean, \$chool of Social Work

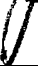

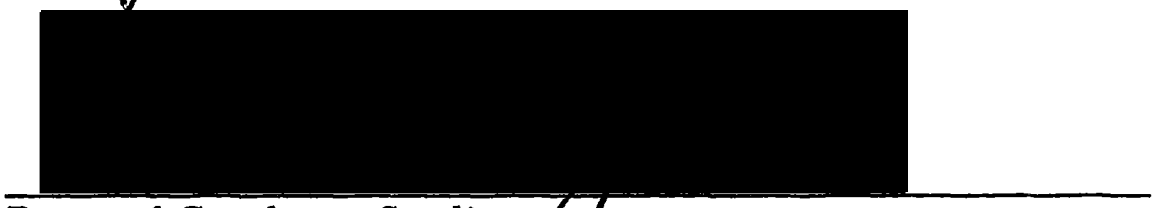

Dean of Graduate Studies

Date thesis is presented March 16, 1967

Typed by Illa W. Atwood for Rose N. Cooper, et al. 
MEDICAL-SOCIAL NEEDS IN A SAMPLE POPULATION OF ELDERLY POST-HOSPITAL PATIENTS

$\begin{array}{ll} & \text { by } \\ \text { Rose N. Cooper } & \text { Marvin E. Hus ebye } \\ \text { JoAnn G. Doyle } & \text { Gladys McCoy } \\ \text { Marie N. Greyerbiehl } & \text { Josephine McWhirter } \\ \text { Guy H. Hancock } & \text { David H. Orvedahl }\end{array}$

A GROUP PROJECT

submitted to

POR TLAND STATE COLLEGE

in partial fulfillment of

the requirements for the

degree of

MASTER OF SOCIAL WORK

June 1967 
TABLE OF CONTENTS

$\begin{array}{ll}\text { Chapter Page } & \text { Page }\end{array}$

I. INTRODUCTION 1

Hypotheses $\quad 2$

Definitions 3

Method 4

Researchers 5

Value of the Study Relative to Recent Legislation 5

Post-Hospital Extended Care 6

Post-Hospital Home Health Care Services 7

Rationale for Social Services for the Elderly Patient 8

Limitations $\quad 14$

$\begin{array}{ll}\text { Summary } & 15\end{array}$

II. A SEARCH OF THE LITERA TURE 16

Method of Surveying Literature 16

Criteria for Limiting Search 17

Background Studies $\quad 18$

U. S. National Health Survey 20

Empirical Studies: Pre-Discharge Hospital Services 21

Empirical Studies: Functioning of the Post-Hospital Patient 24

Research: Prediction of Post-Hospital Needs 28

General Literature $\quad 30$

Conclusion $\quad 32$

III. METHODOLOGY 36

Designing and Planning $\quad 36$

The Sample $\quad 38$

The Schedule $\quad 39$

Pretests and Training $\quad 40$

Collecting the Data 4.1

Tabulating $\quad 43$

Analysis of the Data $\quad 45$

Reporting 46 
TABLE OF CONTENTS (Continued)

Chapter

Page

IV. FINDINGS: DESCRIPTIVE

The Respondents

Living Arrangements

49

Leisure Time

51

Vocational Adjustment

54

Finances

5.5

Adjus tment to Illness

V. FINDINGS: INFERENTIAL

Hypothes is I

Hypothes is II

Hypothes is III

73

Hypothes is IV

75

Summary

78

$\begin{array}{lr}\text { VI. CONCLUSION } & 80\end{array}$

Summary of Major Findings $\quad 80$

Values of the Study $\quad 82$

Critique $\quad 85$

Suggestions for Further Research 88

$\begin{array}{ll}\text { BIBLIOGRA PHY } & 9.1\end{array}$ 


\section{LIS T OF TABLES}

Table

Page

I. Years of Schooling

II. Did You Use Anyone for Help?

III. Leisure T'ime Activity

IV. Average Monthly Income of Patients Interviewed

V. Number of Income Sources

VI. Kinds of Treatment Prescribed

VII. Monthly Amount Spent on Medicine

VIII. Types of Treatment Prescribed 


\section{MEDICAL-SOCIAL NEEDS IN A SAMPLE POPULATION}

OF ELDERLY POST-HOSPITAL PATIENTS

\section{CHAPTER I}

\section{INTRODUCTION}

The Elderly Post-Hospital Patient Project is a descriptive, exploratory and inferential study of psychosocial and medical needs of two samples of elderly patients discharged from the Kaiser Foundation Hospital at Portland, Oregon, still living in the metropolitan area.

The Study Group, which will be described in greater detail later in the study, consisted of 20 patients, 65 years of age or older, discharged from Kaiser Foundation Hospital during March, April, May and June, 1965, adjudged with their doctors as having a high probability of need for post-hospital skilled nursing care.

A Control Group included 43 patients 65 years or older who had been discharged from the Kaiser Foundation Hospital during the same period as the study group, in each case adjudged not to have a high need for skilled nursing care.

To distinguish from similar studies, the present study was called the Elderly Post-Hospital Patient Project, known hereafter in the text as EPP Project, and was undertaken approximately one 
year and four months after the patients' discharge from Kaiser Hospital.

\section{Hypotheses}

The EPP Project sought among other things to determine factors associated with the need for a social worker to deal with problems of the aged. A basis might be developed for assessing patients' needs as one consideration in distributing the time of a social worker, or whether or not to hire one.

The Kaiser Study, from the general medical economics field, sought to develop an objective measuring instrument of the posthospital needs of a known population. The EPP Project was an empirical test of this study to determine if revisions in this instrument were indicated.

Another dimension of the EPP Project was to compare the characteristics of the study group and the control group. If both groups were determined to have similar characteristics then the definition of their needs would be applicable to the total population of elderly post-hospital patients discharged from Kaiser Foundation Hospital.

The EPP Project also sought to compare its findings with those of the New York Study which was reported by Schwartz, Henley and Zeitz (18). 
There were four general hypotheses. The first hypothesis was that those who were adjudged by their doctors as having more medical needs (study group) also have more social needs. The second hypothesis was that the medical and social needs of the study group were the same as the medical and social needs of the control group. The third hypothesis was that the medical needs at the time of discharge were the same as the medical needs approximately one year and four months after discharge. The fourth hypothesis was that the needs of the study and/or control group were the same as those determined by the New York Study.

\section{$\underline{\text { Definitions }}$}

Psychosocial refers to the "interaction between inner psychological and outer social components in the individual's development and function." (12, p. 4-5)

Medical needs referred to in the EPP Project were those items specified in the schedule such as medication, special diet, problems in ambulation, restricted activities in daily living, together with other needs elicited by open-ended questions.

The N. Y. Study, published in 1964 was an assessment of nursing and psychosocial needs of a random sample of 220 patients. This sample was selected from a population of patients who had appointments with the New York Hospital General Medical Clinic 
during a three month period in 1958. These patients were 60 years of age or older and had two or more diagnoses of chronic disease. The Kaiser Study, Greenlick, Hurtado and Saward (10), conducted in 1965 was an exploratory study of a method for estimating the need for skilled nursing service in a population after discharge from hospital. One group evaluated in the Kaiser Study was composed of dischargees 65 years of age or older. It was from this group that the EPP Project selected its samples.

Kaiser Foundation Plan. A community, voluntary, prepayment insurance plan for medical and hospital care.

\section{Method}

The schedule used for the EPP Project was based on the schedule used in the N. Y. Study and covered six areas. The factors considered were background information, living arrangements, use of leisure time, vocational adjustment, finances, and adjustment to illness. The schedule was completed by conducting interviews with the patients in their homes. Interviewees were selected randomly for the researchers in an effort to minimize bias and a total of 63 persons were interviewed. The questions which arose during the study were brought to the project members for discussion and resolution.

Although all members participated in gathering, computing 
and analyzing the data, specific leadership responsibilities were delegated to individual members. An editor and co-editor were assigned to each chapter of the project.

\section{Researchers:}

The project was undertaken by eight graduate students under the guidance of a faculty project director. Five of the eight members had previously had direct experience in working with this age group in State Public Welfare and Public Health Departments. One member had participated only in volunteer activities with older people.

Value of the Study Relative to Recent Legislation

The needs of the person 65 years of age or older received new emphasis as a result of 1965 Social Security amendments. Planning in the area of health services for this age group was imperative. The 1965 Social Security amendments established a broad program of health insurance, known popularly as "Medicare, "for people 65 years old or older. The legislation would have its importance for younger people as well since it would provide services for them in later years. Plans were being considered also to extend the coverage to those in the younger disabled category and to survivors of those covered by Social Security insurance. According to the 
U.S. Department of Health, Education and Welfare (26) the 1965 amendments provide for two kinds of health insurance:

1. Hospital insurance-This insurance would help pay the hospital bills. The benefits included payment for up to 90 days in a period of illness. The program paid for covered services during 60 days of care in a participating hospital except for the first $\$ 40.00$ during a period of illness. If hospitalized for more than 60 days during a period of illness, the program would pay all but $\$ 10.00$ daily for covered services during an additional 30 days of care.

2. Medical insurance-This insurance would help pay for doctors' services and for a number of other medical items and services not covered under the hospital insurance program. The medical insurance program was voluntary. Individual premiums of $\$ 3.00$ monthly were required for this coverage.

Of special interest to those engaged in implementing this legislation was the provision for post-hospital extended care and post-hospital home health care services.

Post-Hospital Extended Care. The program would provide care in the kind of skilled nursing home or part of a hospital which qualified as an extended care facility. After a hospital stay of at 
least three days, the program paid for 20 days of extended care during a period of illness. The program would pay all but $\$ 5.00$ daily for an additional 80 days.

Post-Hospital Home Health Care Services. The program would pay the cost of up to 100 visits in the 365 days after discharge from a hospital after a stay of three days or more or from an extended care facility, if these services were furnished under an approved plan. Services of visiting nurses, physical therapists and other health workers (but not doctors) who would come to the home to furnish health care services were covered. Doctors' visits were covered only under the voluntary medical insurance plan. The provisions of this new government health insurance made necessary some valid estimate of the future demand for both hospital and post-hospital services for those covered by this legislation. Some indication of priority needs were determined in the EPP Project.

Some home care programs had been in operation under private auspices for several years. One example was the home care program carried on by Montefiore Hospital in Pittsburgh, Pennsylvania. Many more programs were being developed at the time. A report in Medical World News, March, 1965 (21, p. 63-65) states:

Home care offers distinct advantages to the patient and not all of them are economic. When the special facilities of the hospital are no longer needed, its rigidity and chilliness are 
often better exchanged for the flexibility and warmth of the home. . . The average home-care cost per day is one fifth or one fourth of the average hospital cost per day. This is a saving of such magnitude that, all other factors being equal, it demands attention from all concerned with better, more economical patient care.

The impetus given by the new legislation might encourage new types of medical services for all. Research and planning would be necessary to anticipate the needs as these programs became more prevalent. This study, while primarily concerned with the needs of the elderly, might give some direction in future planning for expanded services for a broader segment of the population.

\section{Rationale for Social Services for the Elderly Patient}

The EPP Project sought to ascertain the kinds, extensity and intensity of social and medical needs. Kaiser Foundation Hospital had no social services available to its patient population at the time the EPP Project was conducted. Medical needs, which are the primary focus of the physician, are not the only disabling factors in a person's life. Examination of the findings of the study made it apparent that other needs such as economic security, something to do, a suitable place to live, having, close family relationships, all contributed to a sense of well-being.

Gordon (9, p. 97-101) suggests:

If illness is conceived of as a total process, then treatment must be conceived of as a total process and the patient's 
social environment must be considered a part of the treatment process. In addition to prescribing medical treatment, the physician should prescribe the social response to the ill person. However, it is not enough for the doctor to prescribe a social response; just as he checks to see whether his medical prescriptions are being followed, he must determine by judicious probing, if his social prescriptions are being followed. The prescribing of social response to an illness condition is something most doctors are reluctant to do because of lack of time and lack of knowledge. Nevertheless, social prescriptions are an essential part of the treatment process and cannot be delegated to those who have no role in the process. On the other hand, those of us interested in studying the social aspects of illness should attempt to provide physicians with the knowledge to make social prescriptions.

A combination of medical and social services as indicated above contribute to a holistic approach toward helping the patient who does not have the resources to meet his own needs.

Medical social work had existed in our big-city hospitals and outpatient clinics for many years. It had also been included in some home health care programs.

The medical social worker accepts responsibility for the following: authoritative definition of the social situation of the patient; identification of the social forces and factors which are exerting influence upon the etiology and treatment of the patient's health problem; selection of appropriate measures of intervention directed toward modification of factors which may have adverse consequences for the patient's care and recovery; participation in joint treatment planning and evaluation of treatment outcomes; 
and finally, the execution of social treatment within the goals and structure of a jointly developed treatment plan (14). The philosophy, ethics, and theory of the profession of social work are included in these functions.

A statement of essential values of social work was made by Boehm (4, p. 36).

Social workers are concerned with meeting basic human needs in the social realm. This concern is viewed not as an end goal of social work, but rather as a means to an end. This position is based on the view that the satisfaction of basic human needs is an essential condition for the attainment of human dignity and constitutes a necessary basis for individual self-fulfillment, the goal of social work as well as of other professions. The expression of basic human needs and the content of living are culturally conditioned. They vary from society to society, from time to time, and within societies may vary from group to group.

. . . Such a view of social need would lead to a concept of social work activities as ongoing and essential for the effective functioning of individuals and groups in society. This view also implies that social workers will shift their focus of professional activities: to new needs as they arise from the ever faulty interaction between individuals and social institutions.

It is the nature of social work to participate in the identification and elimination of the gap that hampers the individual self-fulfillment. In the United States and Canada it can be assumed that it is primarily the complexity of social life and/or the coexistence of conflicting value systems which make it difficult for social institutions to keep pace with meeting existing as well as emerging social needs. In other cultural contexts, such as technologically underdeveloped areas, social needs may be the result: of primarily deficient material resources.

The attempt to meet basic human needs of older persons has 
received new emphasis in social work. In 1960 there were 16, 560, 000 people in the United States age 65 or older. It was estimated that by 1970 there would be $19,571,000$ people in this age range, or $9.39 \%$ of the population, and by $1975,21,171,000$ or $9.40 \%$ of the total United States' population (24). Services to people in this age group have been neglected in comparison with other segments of the population.

There has been an inclination in the past to stereotype the aged person. To many people, old age is equated with the decline of sensory acuity, weakness, sickness and death. This has caused unwarranted pessimism and attitudes of hopelessness about old people. As a result, services to this age group have only recently gained in number and prominence.

A study was made in 1961 of social service referrals in the New York Hospital-Cornell Medical Center (23). Although this study was conducted in the same hospital as the N. Y. Study men:tioned earlier in this chapter, this was a separate and independent study with a different focus. One of the aims of this study was to determine what kinds of services were requested and given in the various age groups. It was found that referrals for "medical casework" were made less often in each successive age group. For instance, 47 per cent of the patients under the age of 15 were referred for casework, compared with only 12 per cent of those 
over the age of 70 .

Casework has been regarded as a service that is especially effective in helping. clients who possess some self-awareness, ego strength, adaptability and motivation to change. It has been . suggested that the older population subject to chronic disease, social disorganization and other stresses is less amenable to casework. As expected, the majority of patients with chronic and terminal illness were in the older age groups. However, these illnesses at other times of life cause social problems (isolation, increased dependency needs, financial distress) similar to those characteristic of old age. Thirty-six per cent of the Cornell patients received help in "planning medical care"--that is, intensive short-term casework.

According to the report of the White House Conference on Aging (29, p. 170):

Older persons for the most part have the capacity to lead independent and useful lives, enriched by a life-time of experience, but as a group they encounter great obstacles to the satisfaction of these needs. These may include: sharply. reduced income, ill health, physical handicaps, loss of family and friends, unsuitable living arrangements, loneliness, and isolation from community affairs.

Some [persons] are able to avoid or overcome these difficulties alone or with the help from the family. For a great many, however, effective resolution of these difficulties can be achieved only in part by the individual or family effort. A great many problems encountered in aging require some degree of external help. It is to provide this help as it is needed that our social services have developed. 
When an older person does encounter problems in the area of social need, he often lacks the resources of the younger person needed to cope with the difficulty. Illness or acute physical symptoms suffered by the older person increase expenses for medical care, reduce the patient's ability to mobilize people around him for help and comfort, make it impossible for him to use his usual avenues of leisure satisfaction, or change a mildly inconvenient living a r rangement into a hazardous and unmanageable one. These are all areas in which the social worker, particularly the social worker in the medical or clinic setting or home care unit can be helpful.

The increased numbers of persons 65 years of age or older as well as the implementation of Medicare has made it desirable that those in administrative positions and other professional personnel be aware of the kinds, seriousness, and extent of needs in order to plan effectively to meet these needs.

The Kaiser Study, which indicated needs at the time of hospital discharge, was found by the EPP Project to have some validity in predicting significant medical as well as social needs of the elderly post-hospital patient.

The EPP Project attempted to add other dimensions to the Kaiser Study by gathering information about emotional and environmental needs as well as current medical needs. 
Limitations

The EPP Project had certain limitations. All of the patients were at least 65 years old; therefore, the findings could not be applied to the general population. The sample was not taken from the general public but certain occupational, educational and income groups were represented. It is possible that membership in the Kaiser Health Plan provided more health care than that received by the general populace in this age group as visits for medical care were not limited and total costs per visit-were inverse to the number of visits, in contrast to general practice.

The sample size was limited by the Kaiser Study. The original group had been larger but after approximately a year and four months some members of this random sample had died, others had moved from the metropolitan area, and others were too ill or incapacitated to be interviewed. The study group was limited to the 20 patients available for interviewing.

In viewing the EPP Project one should consider that it was a short-time study. A similar study over a longer period of time could vary the outcome. Some medical needs identified by the doctors at the time of discharge were relieved due to the lapse of time. Also there were needs evident at the time of the EPP Project which did not exist at the time of the Kaiser. Study. Since the 
patient 65 years of age or older has more frequent and serious illnesses than the general population, we would expect to find that the longer the period of study, the more severe and urgent the needs and the higher the rate of loss from death.

\section{Summary}

The EPP Project was an exploratory, descriptive and inferential study of two samples of a population of post-hospital patients in the metropolitan area of Portland, Oregon. This project was an empirical test of the Kaiser Study and comparison was made with the findings of the N. Y. Study.

In general the hypotheses were borne out but require further elaboration discussed throughout the study.

The EPP Project was limited by time, size of sample and specific characteristics of the population studied, such as age, social and economic traits. 


\section{CHAPTER II}

\section{A SEARCH OF THE LITERATURE}

In the early stages of the EPP Project, plans were made to search the gerontological literature so that the project might be seen from the perspective of the field as a whole.

\section{Method of Surveying Literature}

The EPP Project members jointly assumed responsibility for searching the literature. Initially, each member read and evaluated a group of assigned readings that were obtained from the Medical Care Reference Library at Kaiser Foundation Hospital. Emphasis was placed on finding empirical material relating to the elderly post-hospital patient.

Individual assignments were also made for searching major books, journals, and abstracts in the fields of social work, psychology, sociology, geriatrics, gerontology, medicine, public health, and medical economics.

In order to gain insight into the problems of the discharged geriatric patient, project members consulted with individuals in the community who were professionally involved with the aging. These included two public health gerontologists, the County Health Officer, a medical director of the State Board of Health, the 
medical-social consultant on aging with the State Board of Health, and several nursing home administrators.

\section{Criteria for Limiting Search}

The beginning point and focus in the search of the literature was the period from 1960-1966, using citations in this material to locate possible significant studies of previous periods. Limitations of time, the great increase in number of studies, and material actually available dictated this decision. In all, several hundred resources were evaluated.

Kent (13, p. 202) pointed out the dramatic change that had taken place in this area of knowledge by comparing the number of bibliographical items in the Journal of Gerontology in a two year period in the early $1950^{\prime}$ s and a corresponding period in the early 1960's. The Journal listed 4,726 items in the first period and 7,321 in the second.

The latter decade saw significant activity on behalf of the aging. The Kerr-Mills Act of 1960 showed new cooperation between federal and state governments in providing health care for older people (25). The program was state administered, and its quality of operation was influenced by local factors. It offered medical assistance to low-income individuals who could pass a means test.

Kerr-Mills was a step towards providing medical care for 
the aged, but was far from being comprehensive. The inadequacy of the program to meet the health needs of a majority of older people was reflected by great activity in Congress during the early 1960's to establish a national program of health insurance.

The 1961 White House Conference on Aging represented another step in the direction of a broadly expanded social policy in regard to older persons. This conference sought to identify the problems and needs of the aged and offer practical solutions.

The Older Americans Act of 1965, a major piece of legislation, made provision for the Administration on Aging within the Department of Health, Education and Welfare. The establishment of the Department indicated the Federal Government's long-range concern with the problems of the elderly. In addition to these developments, implementation of Medicare legislation in July, 1966 signaled the coming of a new era in the field of medical care for the aging.

\section{Background Studies}

Two comprehensive studies of the general health needs of the non-institutionalized elderly were published in the early $1960^{\prime}$ s. Shanas (19) summarized the findings of a 1957 survey of health, based on a nationwide sample of persons 65 years of age and over and those individuals to whom older persons could turn in a health 
crisis. In her interview study of 1,700 older persons, she reported that over 73 per cent of the men and almost 78 per cent of the women said that they agreed with the statement, "The way things are now, most people can expect to feel pretty good when they're 70. " Even among the 175. respondents classed as "very sick," over 62 per cent agreed with the statement.

Nothing in this survey upheld the stereotype of the aged as a collection of sick, ailing, and useless individuals. Shanas (19, p.

182) concluded:

The American stereotype of the elderly as sick, infirm, and indigent is not validated by this survey. Some people 65 years and older are sick, infirm, and indigent, but most are functioning well physically and mentally. These people look first to themselves and their own resources, and then to the programs of the federal government for the means by which they may live out their lives in dignity and with self-respect.

Blenkner, Jahn and Wasser (3) attempted to ascertain the usage of social service and health agencies by older people. In this broad study of individuals 60 years of age and over, health functioning was explored. It was found that most of the older people interviewed were not seriously ill. Those who had medical problems were able to cope with them:

Older people, it would seem, have a more modern concept of health than some of those serving them; they see it in terms of functioning, not in terms of clinical pathology (3, p. 69). 
U. S. National Health Survey

Statistics from the National Health Survey conducted in the late $1950^{\prime} \mathrm{s}$ have aided in understanding aspects of medical care related to the post-hospital patient. For example, a 1958 study (27) described the Survey's findings regarding short-stay hospital statistics. Of value to the EPP Project was information relating to the discharge population and days of hospitalization for older individuals.

The data for this report were based on interviews conducted during the period from July, 1957 through June, 1958 covering approximately 36,000 households comprising 115,000 persons. Individuals in the age range of 65 to 74 accounted for 6.9 per cent of discharges and those 75 and over for 3.6 per cent of discharges.

Average length of stay for those 65 to 74 was 14.3 days and for those 75 and over 15.6 days. It was noted that in the 65 to 74 year category average length of stay was 12.8 days for females, whereas for males in the same category the length of stay was 15.8 days. For both male and female groups in the 75 year and over category, however, the length of hospital stay was about. the same.

Another study from the National Health Survey described findings related to persons receiving care at home (28). Data for this report, collected during the period from.July, 1958 through 
June, 1959, were based on about 37,000 household interviews covering 120,000 persons. The survey showed that the rate of persons receiving care at home rises consistently from about two per thousand at the lower ages to 87.7 per thousand at age 75 and

over. In the age range from 65 to 74 years, 47.2 per cent of males and 52.8 per cent of females reported receiving personal care at home. In the age range of 75 years and over, 35.4 per cent of males and 64.6 per cent of females were reported to have received some form of care at home. Persons 65 years and over constituted the largest group receiving care.

\section{Empirical Studies: Pre-Discharge Hospital Services}

Some empirical studies focused on the relationship of hospital rehabilitative and social services to the later functioning of the elderly discharged patient.

Steinberg and Frost (20) conducted a follow - up study of a group of discharged geriatric patients who had been given intensive rehabilitative services before being released from a general hospital. The study took place in 1962 in St. Louis and involved 43 patients--15 men and 28 women. The individuals ranged in age from 60 to 84 years with an average age of 72.3 years.

The patients spent an average of 87 days in intensive rehabilitative services before being discharged. Treatment consisted of the 
services of social workers, physical therapists and occupational therapists in addition to physicians and nurses.

Steinberg and Frost (20, p. 163) found that 30 of the 43 patients (70 per cent) were living in their own homes. They concluded that intensive rehabilitation of the geriatric patient "is a worthwhile endeavor, that it should be started early and that it may keep many patients out of custodial institutions."

Goldmann (8) found that only 21 per cent of patients in five hospitals who were discharged with diagnoses necessitating longterm post-hospital care had been referred to social service departments. He also found that only four per cent of those who occupied private and semi-private rooms received social work help. With regard to the latter finding, Goldmann questioned whether the lower classes were more privileged to receive medical social services:

Apparently the concept underlying the introduction of the Lady Almoner system continues to exert a profound influence on contemporary policy in using casework services. Ward patients are regarded as primary, if not sole, objects of social workers' activities because they have little or no independent income and meager other resources. Such a policy would be excusable if financial aid and service to the "underprivileged" were the principal functions for which social workers are employed (8, p. 77).

He also realistically stated that the overworked social work staff could not begin to approach the task of meeting the needs of the entire hospital population: 
Of course, social workers should not be expected to do the impossible. Extension of activities means more personnel. At present, many social service departments are not staffed well enough to permit much attention to patients in semiprivate and private accomodations, who, after all, make up the majority in the typical non-profit general hospital under voluntary auspices (8, p. 77).

Goldmann reported that most of the work of the social workers centered around the immediate discharge of the patient. His study suggested the value to the geriatric patient as well as to his family of intensive social work service during the long weeks of hospitalization. Such service, using the "full casework approach including social study, diagnosis, and treatment" (8, p. 73) might enable the patient to make a more satisfactory adjustment upon his return home.

Anderson (1) described a study that attempted to measure the results of a team process involving medical and paramedical personnel in the hospital discharge of the geriatric patient. This study utilized data from a 76 bed ward for chronic neurologic cases in a veteran's hospital in New Jersey. A physician, a nurse and a social worker, in sequence, evaluated the patient!s needs relative to his overall functioning.

In addition, each team member had responsibility for preparing the patient for discharge. For instance, the social worker concentrated on casework with the patient and his family as well as on utilization of community resources available for the patient. 
It was theorized that the team discharge process constituted an instrument for improved coordination and provision of services. It was found during the 12 month period of the study that referrals to the Social Service Department increased 60. 4 per cent and discharges increased 47 per cent compared to the previous 12 month period of time. More than 70 per cent of the patients referred to social service were able to return to their own homes. Moreover, the turnover rate in the ward increased 66 per cent. Anderson (1, p. 270) described the philosophy behind the team process:

A favorable climate already existed for assumption of a more definitive approach to the problems of discharge, by virtue of the ward physician's philosophy and clinical practice encompassing the concept of treating the whole person.

The ward physician's respect for contributions of team members and ready willingness to delegate responsibility to carry out various aspects of the program in a climate of free exchange were additional advantages. Further, the conviction that life in a home or in a non-institutional setting is far superior to life in a hospital gradually helped to remove most of the resistance and misunderstanding prevalent among patients, families and staff regarding the feasibility of discharge of the chronically ill.

Empirical Studies: Functioning of the Post-Hospital Patient

In a recently published study about the elderly ambulatory patient, Schwartz, Henley, and Zeitz (18), the N. Y. Study, found a wide range of needs previously unnoticed by the personnel of a 
well staffed, comprehensive care clinic in a large medical center. As previously noted, the EPP schedule was adapted from that used by the N. Y. Study.

Of the total sample interviewed in the N. Y. Study, 17 per cent were said to be on the verge of breakdown in their life situation. Supporting services, particularly those of visiting nurses, homedelivered meals, homemakers and domestic help were urgently indicated. The study posed serious question's concerning the functioning of many older post-hospital patients.

The EPP Project was concerned with many of the same topics upon which the N. Y. Study was based. These included medical needs before and after hospitalization, availability of relatives and/or others to help the dischargee, dietary management and utilization of visiting nurse services. The social aspects of the dischargee's life in such areas as employment, recreation, economic functioning and other activities of daily living. were also explored in both studies.

Rosin and Eddison (17) carried out a study in England to determine changes of functional capacity in a group of geriatric post-hospital patients six months after discharge. Assessment of the functional status of the patient involved use of a scoring system that took account of the following factors: mobility, mental state, incontinence, toilet needs, dressing and feeding, and defects of 
special sensory and nervous functions. Patients were also rated on a social scale which showed their living arrangements, loneliness and dependence on others.

During one year, 132 patients were discharged from the geriatric unit: 99 to their own homes, and the remainder to "residential accommodation." At the time of discharge, 15 per cent were assessed as being able to go outside their home alone. Most of the se patients lived alone. Fifty-five per cent of the total group were ambulatory in the home and could function independently in terms of personal needs. Of those living with relatives, 47 per cent required moderate to considerable personal help.

After six months, a follow-up study was made which revealed that almost one third of the patients had been readmitted to the hospital at some time during this period. Of the whole group, 21 had died, 31 had deteriorated, 60 remained unchanged, and 20 had improved. Little change had occurred in the group of about 25 per cent who required home health services, for six months later they still needed as much help. Rosin and Eddison (17, p. 150) concluded:

The severe disabilities of the hospital geriatric population are related to the chronic and recurrent nature of the degenerative diseases of old age. Many of the patients suffered from several unrelated clinical conditions. The ultimate prospects of an elderly person discharged from the hospital depend both on the overall functional disability and on the social background. Careful planning and coordination of 
after-care services are important aspects of the work of a geriatric department.

The suitability of elderly hospital patients for home care was the subject of a project by Elconin, Egeberg, and Dunn (7). A sample of older patients from a general hospital population was studied to determine how many, would be appropriate for organized medical home care. The subjects were medically indigent patients with prolonged acute or chronic illnesses requiring close medical supervision. The researchers dealt with the pertinent social, ethnic, religious and economic factors which would influence these persons' care at home.

It was found in this four year project that of the hospital patients sampled as many as 14.8 per cent were "medically suitable" for home care. Of those acceptable for home care, however, only 47.3 per cent had homes and/or families willing and able to receive them after discharge. Patients who came to the hospital from rest homes, even though they had families were rarely; accepted afterwards by their families.

The authors (7, p. 1106) described the kind of organized home care program that should be provided for those patients who might safely be cared for at home. They stated that the program consisted of more than a visit by a physician:

Rather it consists of caring at home for the patient who has multiple medical and paramedical needs and, lacking this 
modality, is generally in need of continuous or frequent hospitalization. Organized home care provides the physician with coordinated services necessary to accomplish this level of care in the home. Such services would include home nursing, physiotherapy, social service, portable laboratory facilities, hospital equipment and supplies, and housekeeping help. .

If a patient required more than one doctor's visit, nursing visit, or portable laboratory visit per day, he would not be acceptable for the home care program.

Research: Prediction of Post-Hospital Needs

A project conducted by Greenlick, Hurtado, and Saward (10), previously referred to as the Kaiser Study, played an important role in the research design of the EPP Project. The EPP study group, i. e., those patients predicted to have medical and social needs upon discharge, were selected from the substrata of persons 65. and over utilized in the Kaiser Study. By evaluating the needs of the discharged patients one year and four months after the predictive formula was used, the EPP Project added a new dimension to the Kaiser Study--that of time.

The Kaiser researchers conducted a methodological study which had the purpose of utilizing medical, social and economic data to develop an objective measure of the need for post-hospital services. The study design consisted of three stages: development of objective criteria for measurement of physical condition 
and functional capacity, evaluation of a probability sample of selected discharges on the bàsis of the criteria, and analysis of these evaluations and formulation of estimates of need in the population.

A panel of 15 physicians helped to delineate the criteria used to estimate potential need. A sample of 492 patients was taken: from the population of those who had been recently discharged from Bess Kaiser Hospital in Portland, Oregon.

For purposes of the study, these patients were assembled into five strata, one of which consisted of patients 65 years of age and older. Concerning this elderly sub-sample, the study predicted that 18 per cent of this group were estimated to fall into a category designated with a high probability for post-hospital needs. Based on this sample, it was further estimated that approximately 18 per cent of the 3.5 million hospital discharges in the United States for people 65 years of age and older might be candidates for some form of post-hospital skilled nursing care.

The Kaiser Study (10, p. 1198) concluded with the suggestion that the method developed by the project might be promising for evaluating hospital discharge populations for post-hospital need:

By utilizing various sets of criteria and varying sample fractions the general approach could be applied to many similar problems. The important task of validating the method and estimates derived using the method is left to the future and perhaps to other researchers, but it is 
possible that even these preliminary data can be of some immediate importance in the planning and organizing of needed medical care services.

\section{General Literature}

Although emphasis was placed on a search of research literature by the EPP Project, some outstanding professional, nonempirical books and monographs were found that dealt directly and indirectly with the elderly discharged patient.

An evaluation of the post-hospital planning for chronically ill veterans was the subject of an article by a medical social worker, Grace Mehling (16). She described the caseworker's functions in terms of the realities that one finds with older individuals. As an example, after discharge, the patient may often find his family either unwilling or unable to care for him. On the other hand, some patients following hospitalization resist returning home even though they may not require institutional care. The caseworker must also cope with what the community has to offer in the way of resources for the post-hospital patient in relation to what he can afford.

Mehling's article is indicative of the pragmatic approach that has been adopted in the absence of applicable research. As the author (16, p. 85) stated:

An attempt has been made to state realities and to show both 
the positives and negatives as a contribution to the general growing fund of information in the care of the aged and chronically ill.

Also, on a practical level, Leeds (15) has presented the social work profession with a distinct challenge. Leeds stressed the importance of the caseworker in the hospital and especially in preparing the patient to function effectively following hospitalization. He alleged that the social worker was indispensable in rendering services to the older person--especially because of the physician who."has a shorter span of patience with the older person, who is less satisfying, slower to heal, quicker to relapse, so near to death. " (15, p. 8) Leeds suggested that the physician may reflect cultural values in general that tend to overlook the needs of the older person.

In the 1960's it had become increasingly clear that social services must be provided in medical setting. Heyman (11) indicated the growing concern with a hospital's recognition of the patient's social needs. The importance of working with the geriatric patient prior to discharge was presented. The author lamented the shortage of trained personnel to meet this and other problem areas.

Travis (22) also focused on social services in the medical setting. She attempted to correlate medical theory and practice with that of social work. The author described and evaluated the role of the caseworker in helping the older patient both before and 
after discharge.

Butts (5), in her study of casework in public assistance medical care, concentrated on the medico-social problems of older individuals. With regard to the elderly patient, she stressed the role of the caseworker in post-hospital planning:

The caseworker's evaluation of the person's whole social situation may show that arrangements for adequate care can be made available in his own home or other noninstitutional place where he prefers to remain. These facts are not the physician's responsibility to assemble. When they are presented to him as an alternate plan, he is then able to discuss with the caseworker whether the essential level of medical care can be provided under the proposed circumstances (5, p. 37-38).

\section{Conclusion}

When the EPP Project had finishedits search of the literature, few empirical studies which were pertinent had been found. Perhaps the paucity of empirical material reflected the youthful state of the field of gerontology. As Birren (2, p. 3) pointed out, "Research in aging is a late arrival in science, trailing the field of growth and development by several decades."

Research applicable to the EPP Project centered with two general topics: pre-discharge preparation of the geriatric patient and post-hospital functioning of the released patient.

Studies cited relating to pre-discharge activity all encouraged the use of hospital rehabilitative and social services in preparing 
the older person to function in the non-institutional setting. Goldmann (8) evaluated the extent to which geriatric patients were exposed to social services and concluded that more should be done to prepare the patient for post-hospital life. Anderson (1) investigated the usefulness of the team process in preparing older patients in a veterans hospital and alleged that the process was instrumental in helping many patients to make a successful transition to the noninstitutional environment. Steinberg and Frost (20), from their research concluded, that intensive rehabilitation would enable many patients to remain home after discharge rather than have to face soon afterwards the prospect of further hospital or custodial care. The EPP Project did not attempt to evaluate the effect of predischarge services on the later functioning of the released patient. If, as the studies cited alleged, pre-discharge services improved later functioning, it would seem that post-discharge services might have a similar effect. No research was found as to which was the more valuable for the post-hospital patient.

Research also focused on the functioning of the post-hospital patient. The N. Y. Study found medical and social needs in 17 per cent of the patients studied. Rosin and Eddison (17) found that only 15. 1 per cent of their study group had made any improvement after discharge and, not counting those who died, 23.4 per cent had deteriorated in their functioning. Differences between the findings 
in these two studies possibly reflect socio-economic factors as well as the variable of the passage of time after discharge.

The EPP Project differed with both studies with regard to the socio-economic factors and the passage of time. Rosin and Eddison evaluated the functioning of patients six months after discharge whereas the EPP Project evaluated medical and social needs more than a year after discharge. As such, the EPP Project was: assessing one measure of the validity of the predictive formula proposed by the Kaiser Study.

Elconin, Egeberg, and Dunn (7) evaluated the potentiality of geriatric patients for non-institutional functioning in view of organized home care services. They alleged that 14.8 per cent of those who would have to remain institutionalized could be discharged if the community were to offer essential home care services. The EPP Project did not focus on home care services per se in the community, but the presence of medical and social needs in the study group reflected to some extent need for home care services.

The Kaiser Study proposed criteria by which medical needs might be predicted in a geriatric population at discharge. The EPP Project, in addition to assessing the validity of the Kaiser criteria, also predicted changes to occur after one year. As the population of older citizens rapidly increases and as the lifetime of the elderly steadily lengthens, predictive criteria will be invaluable for the 
future provision of medical and social services.

The EPP Project, as well as other studies evaluating posthospital functioning of elderly patients, showed that there was a significant proportion of older persons who had medical and social needs. The EPP Project envisioned that social workers might help such individuals toward better functioning following hospitalization. 
CHA PTER III

\section{ME THODOLOGY}

\section{Designing and Planning}

The major objectives for the EPP Project were to explore further the medical and social needs of an elderly, post-hospital discharge population and to determine the need for social service and nursing service. The design included a study group of patients, 65 and older, perceived by the doctors to have more medical needs upon discharge, and a control group from the general elderly discharge population, not so judged.

Discussions were held in the early stage of the study around the objectives of the study, the research situation in which there was expected some percentage of attrition and deaths, and the most adequate technique for arriving at the necessary information. During these discussions the group proposed many null hypotheses of no difference between the two samples. When these were focused under general headings, a pattern evolved which reflected the group's thinking under six specific areas.

Within these general objectives the group perceived four central questions. Was the prediction formula successful in differentiating need? Were the predicted variables the only factors 
accounting for the differentiation of need or were there social and economic variables involved? Did the predictions hold up beyond the immediate post-hospital period? To what extent were the social, economic and medical needs of the EPP group comparable to those same needs found in the N. Y. S tudy?

The hypotheses to be tes ted were as follows:

1. Those patients designated by the doctors as having more medical needs also had more social needs.

2. The medical and social needs were the same for the control group as for the study group.

3. The medical needs at the time of discharge were the same as the medical needs one year and four months after discharge.

4. The needs in the EPP Project were the same as the needs in the N. Y. Study.

Review of the literature was the first task assigned by the group. All members participated in the review as described in the second chapter. The principal object of the search was for empirical studies relating to the needs and conditions of elderly persons released from hospital care, but the group was also interested in searching for concepts or factors which might be employed in the present study. 
The Sample

From the stratified sample of patients released from the hospital in the late spring of 1965, the Kaiser Study had distinguished two groups of patients over 65. One of these was designated by doctors as having high probability of medical need while the other had not been so designated.

Limitations of time and personnel made it impossible to interview the two groups in their entirety. A control or contrast group was drawn from all patients over 65 discharged during March, April, May and June of 1965, less those eliminated due to death, less those adjudged to have high need for skilled nursing service. Starting with a point determined from a table of random numbers every first and third case (by toss of coin) was taken.

The study group consisted of all those with designated high need, with attrition from death, refusal to be interviewed or los s of residence in the metropolitan area.

For certain purposes, subject to later tests there was therefore a total group of releasees consisting of a study group and a contrast group.

The total initial sample yielded an $\mathrm{N}$ of 99 , with 38 in the study group and 61 in the control group. From the total sample 23 had died, six refused to be interviewed and six had moved out of the 
area. This left a total of 63 from whom data could be collected-20 in the study group and 43 in the control group.

\section{The Schedule}

During the review of the literature it was discovered that a similar study had been made in New York. Permission was granted to adapt their schedule to the use of the.EPP Project. The social service questionnaire and the nurse's interviewing guide were assimilated for the EPP Project.

The rationale for comparing the N. Y. Study was that the EPP Project might be more useful if it could build on a similar study already in the field. This practice would yield the constance or variability of different hospitals. It would also add to the body of theory in the field.

The N. Y. Study was long and detailed, conducted with patients attending clinic. The EPP schedule was administered in the place of residence of the respondents. The effort was made to avoid being unduly tiring to the respondent by keeping the length of the interview as short as possible.

Each item in the schedule was thoroughly discussed. Some questions were added, some modified, some omitted. The intention was to use sufficient areas of non-medical need with which to correlate the medical needs. The aim was to reflect a holistic 
view of human needs in the areas of living arrangements, use of leisure time, financial functioning, vocational adjustment and medical needs. Decision was reached by group concensus.

The group was constantly alert to possible relationships and ways in which a social worker might be employed. To this extent the study was exploratory as well as inferential, descriptive and analytical.

The first draft of the schedule proved to be too long with too many items in some areas, not enough built-in checks for accuracy and ambiguous wording in some items.

Again the group discussed each item until consensus was reached as to its disposition. A second draft was made and used in a pretest.

\section{Pretests and Training}

A preliminary pretest was conducted in role play by members of the group as interviewer and interviewee behind a two-way mirror. The rest of the group observed and noted ideas for revision.

Awkward questions were discovered, ambiguities came out, regrouping of related questions and finer differentiations made, along with improvements in the ease of recording. Further discussion imposed more revision and interpretation. The corrections 
were incorporated and plans made for another pretest with an elderly post-hospital patient.

Each member interviewed a post-hospital patient taken from the general hospital population but not a part of the sample.

The pretest and later discussions provided some refining of techniques and skills for the already trained interviewers. The fact that they were all social workers also meant they used similar techniques and skills, in addition to training. Experiences were shared both formally and informally, and during the conduct of the research interviews to improve consistency of method and interpretation.

\section{Collecting the Data}

In preparing the respondents for the interview, a letter was mailed to each one. It explained briefly the purpose of the project and stated a possible time for an interview in their place of residence. When possible, a phone call preceded the date for confirmation. The six refusals came at the time of the calls; however, some resistance was overcome by the power of persuasion. Two patients did admit the interviewer when she arrived. Two patients called the Kaiser Research Center to confirm the legitimacy of the interView before the date set. More such calls had been anticipated due 
to spurious interviewers in the community arousing suspicion at that time.

Interviews were assigned on the basis of the nearness of the patient to the interviewer's residence. The rationale for the assignments was that a resident of the area would have a greater understanding of the social setting, including type of housing, distance of interviewee from stores, church, leisure time facilities and access to public transportation.

The interviews were held in the place of residence of the patients. One respondent questioned the interviewer from inside, with the door ajar, for 25 minutes before admitting her to the house. Since privacy from others in the household was not required, often the spouse or child of the patient would be present and would help with the questions. At the beginning of the interview the interviewer would again explain the purpose of the project and the confidential nature of the information and answered questions concerning the project or the schedule.

A few researchers encountered some coldness and resistance at the point of entrance to the interview. However, all reported a warming effect during the interview. By the end, respondents were relating to the interviewers as to a friend. Some expressed a desire for a return visit.

There were six respondents who could not be interviewed. 
One was senile and incapable, another did not have the time, one was advised by a child that it might not be safe. The others simply refused.

The time required to complete a schedule was about one to one and a half hours. One interviewer took two and a half hours to complete one schedule due to the respondent's talkativeness.

Call backs were minimal, suggesting the effectiveness of the group's preparation.

The interviewer recorded responses by circling numbered or lettered choices or writing out verbatim responses. Space was provided on the schedule for an evaluation of needs observed by the interviewer.

Interviews were blind to prevent bias on the part of the interviewer. That is, the interviewer did not know whether the subject was in the control or study group.

It was not until completion of all the schedules that they were separated into study and control groups.

\section{Tabulating}

Each interviewer checked his own schedules for responses to all items. Additional checks at the point of compiling the statistics even so revealed errors which were then corrected and reconciled by going back to the original schedules and differentiating categories 
to include all items.

During statistical computations, cross-checking permitted elimination of dispensable questions because of insufficient responses or differences in interpretation. There were some instances when the respondent did not know or could not remember at the time. In other areas when the question did not apply to all respondents a "No response" category was added for the sake of accountability.

The problem of tabulating verbatim responses in some meaningful way was resolved by a group decision to categorize similar responses under specific general headings.

In the early stages of tabulation small groups worked together tallying the circled responses successively throughout the schedule. Others devised plans for verbatim responses to be decided by the whole group. When the tallying had been completed the group discussed the type of analysis to be used. The data were collected under the section headings where they occurred on the schedule: living, leisure, vocation, economics, medical. Everyone participated in the computations with those more competent in statistics giving aid and directions. 
Analys is of the Data

Analysis of the data took three principal forms. Descriptive findings were in the form of tally, percentage and verbal comparisons by groups and categories of need. Tests of null differences were used to justify combined groupings when legitimacy was in doubt. These findings are reported separately as a part of the descriptive and exploratory nature of the study.

Inferential statistics were used as indicated above, but mainly for testing of null hypotheses bearing on the major research hypotheses. Chi square was used for non-parametric tests and to check the $t$ tests. The $t$ test was used to test equality of means, without correction for unequal vaxiances. Though the sizes of the groups differed, a few early tests indicated that this was not a factor that needed to be considered. The extended median test was used under several differing assumptions about theoretical values, but only the straightforward expectations were employed in reporting.

The .05 level of probability was decided upon partially for traditional reasons and partly because it seemed to be an appropriate level for exploratory purposes. It was considered important not to exclude possible relations by Type I errors. 
Reporting

Two members were assigned the role of editors while the six others wrote the chapters in which the study was reported. The six who wrote worked in pairs, writing and editing.

All chapters were collated, allowing for some duplication that was desirable.

The total group participated in offering material for the chapters as well as editing the completed manuscript.

Much more statistical data were collected than could be used in the analysis. However, the remaining data will be useful in some further research study such as a study of closer correlation or comparison with the N. Y. Study. It may be used to measure the effectiveness of the prediction formula. Or it might be useful for replication in different hospital settings.

Some of the more detailed statistical methodology will be reported in the following two chapters, while in the final chapter a critique of the study's methodology will appear. 


\section{CHAPTER IV}

\section{FINDINGS: DESCRIPTIVE}

This chapter will develop a general description of the population and a description of the data related to the need or lack of need for social work services demonstrated by the sample population. The schedule contained 146 separate items with multiple responses, far too many to be dealt with in detail on an individual basis. Data will therefore be grouped according to basic demographic and adjustment areas.

\section{The Respondents}

From the demographic data it appeared that the study group and control group were similar in composition, and might be treated as a single population in many areas for the purpose of description.

The study and control groups were selected from the same general population of patients, 65 years and over. These patients were discharged from the Kaiser Foundation Hospital, Portland, Oregon from March 15, 1965 through June 30, 1965. All but two of the sample members were participants in the Kaiser Foundation Health Plan, a community voluntary prepayment insurance plan for medical and hospital care. The sample members were all residents of the Portland, Oregon--Vancouver, Washington metropolitan area. 
The study group of 20 consisted of seven men and 13 women with a mean age of 74.0 years. The control group of 43 consisted of 28 men and 15 women and had a mean age of 74.2 years. Nearly all of the sample population were Caucasians. There was only one Negro in the control group, and no Orientals in either group.

A large proportion of both groups were American born, $\mathrm{S}-70 \%, \mathrm{C}-81.4 \%$. There was a greater proportion of respondents in the study group who were born in Scandinavian, German and Middle European countries, S-25\%, C-11.6\%. A second question on the schedule designed as a check for accuracy yielded exactly the same results. Approximately half of the parents of the respondents were foreign born.

Both groups were similar in religion. Protestants and Catholics made up over $90 \%$ of the total sample with the Protestants. heavily outnumbering Catholics in both groups of practicing and nonpracticing members. A slightly larger proportion of Catholics was noted in the study group, reflecting the slightly larger proportion of respondents in the study group born in Middle European countries:

It was determined by inspection that no significant difference existed between the two groups in their current marital status. An equal proportion were widowed in both groups, S-25\%, C-25\%. An equal and large proportion of both groups were married, S-65\%, C $-67.4 \%$. These figures correlate well, and provide a check for 
accuracy, with a second question from the schedule which asked who lives with the respondent. The spouse was named in $70 \%$ of the cases by the study group and $72 \%$ by the control group.

The five per cent difference noted in the study group's responses to the two questions can be explained by the fact that one person in the study group failed to answer the question on marital status, but did answer the second question.

The groups were similar in their level of education. More than half the sample reported from one to eight years of education, S-60\%, C-55.8\%. The proportions decreased progressively through the college level with only one member of the study group and two in the control group reporting a college education. Only two people in the study group and one in the control group had business or vocational training. (See Table I.)

\section{Living Arrangements}

There was no observable difference in the two groups with respect to type of residence. Seventy per cent of the entire sample lived in private homes, with most of the others living in apartments. Only one person in each group was in a nursing home. As noted earlier, $70 \%$ of the study group and $72 \%$ of the control group were living with a spouse. A substantial majority of both groups, $\mathrm{S}-80 \%$, 
TABLE I

YEARS OF SCHOOLING

\begin{tabular}{|c|c|c|c|c|}
\hline & \multicolumn{2}{|c|}{ Study } & \multicolumn{2}{|c|}{ Control } \\
\hline & Frequency & $\begin{array}{l}\text { Percent } \\
(\mathrm{N}=20)\end{array}$ & Frequency & $\begin{array}{l}\text { Percent } \\
(\mathrm{N}=43)\end{array}$ \\
\hline $1-8$ years & 12 & 60 & 24 & 55.8 \\
\hline Some high school & 4 & 20 & 10 & 23.3 \\
\hline Completed high school & 2 & 10 & 3 & 6.9 \\
\hline Some college & 1 & 5 & 4 & 9.3 \\
\hline Completed college & 1 & 5 & 2 & 4.7 \\
\hline \multirow[t]{2}{*}{ Postgraduate work } & 0 & 0 & 0 & 0 \\
\hline & 20 & $100 \%$ & 43 & $100 \%$ \\
\hline
\end{tabular}

C-83\%, were satisfied with their place of residence and had not considered moving.

There was a difference between the two groups in their expressed need for someone to come in and help with the household. Twenty per cent of the study group and ten per cent of the control group indicated such a need. It was also determined by observation that a significantly larger proportion of the study group had used someone for help compared to the control group, S-40\%, C-21\%. 
TABLE II

DID YOU USE ANYONE FOR HELP?

\begin{tabular}{lcccc}
\hline & \multicolumn{2}{c}{ Study } & \multicolumn{2}{c}{ Control } \\
& Frequency & $\begin{array}{l}\text { Percent } \\
(\mathrm{N}=20)\end{array}$ & Frequency & $\begin{array}{l}\text { Percent } \\
(\mathrm{N}=43)\end{array}$ \\
No & 12 & 60 & 34 & 79 \\
Yes & 8 & 40 & 9 & 21 \\
\hline
\end{tabular}

\section{Leisure Time}

There was a marked similarity in the principal leisure activities engaged in by both groups. Watching television programs headed the $\mathrm{lis}$ in both groups as a daily leisure activity, $\mathrm{S}-90 \%$, C $-86 \%$. Lis tening to the radio, hobbies, and sitting and thinking were the next most frequent daily activities.

Letter writing, walks or rides, and visiting friends were the most frequent activities participated in weekly or more by both groups. Religious activities were listed much more often as activities engaged in weekly or more by the control group than by the study group, $\mathrm{S}-10 \%, \mathrm{C}-32.5 \%$.

Movies, libraries, and religious activities were listed most often by both groups as activities they seldom or never attended. 
When asked if there were any particular places outside of the home where they liked to spend time, $40 \%$ of the study group said none, and another $40 \%$ said the home of relatives or friends. The control group's responses were more dispersed among a wide range of activities, but a sizeable proportion chose "none," "relatives' or friends' homes," and "other."

The differences noted between the two groups were in the degree of participation in leisure pursuits that required physical activity or movement by the respondent. The study group consis tently listed sedentary leisure activities more often than the control group. Conversely, the control group regularly indicated they participated in more active leisure pursuits than the study group.

In general there was no highly significant difference between the two groups' leisure time activities. The activities most of ten engaged in by both groups were those done in the respondents' own homes. The activities least often engaged in were those that required the respondent to be out of the home.

Table III on the following page summarizes in greater detail the use of leisure time. The percentage figures in Table III are rounded to the nearest whole number. 
TABLE III

LEISURE TIME ACTIVITY

\begin{tabular}{|c|c|c|c|c|c|c|c|c|c|c|c|c|c|c|c|c|}
\hline \multirow{3}{*}{$\begin{array}{l}\text { Amount of } \\
\text { Participation }\end{array}$} & \multicolumn{4}{|c|}{ Daily } & \multicolumn{4}{|c|}{ Weekly or More } & \multicolumn{4}{|c|}{ Monthly or More } & \multicolumn{4}{|c|}{ Seldom or Never } \\
\hline & \multicolumn{2}{|c|}{ Study } & \multicolumn{2}{|c|}{ Control } & \multicolumn{2}{|c|}{ Study } & \multicolumn{2}{|c|}{ Control } & \multicolumn{2}{|c|}{ Study } & \multicolumn{2}{|c|}{ Control } & \multicolumn{2}{|c|}{ S tudy } & \multicolumn{2}{|c|}{ Control } \\
\hline & $f$ & $\%$ & $f$ & $\%$ & $f$ & $\%$ & $f$ & $\%$ & $f$ & $\%$ & $f$ & $\%$ & $f$ & $\%$ & $\mathrm{f}$ & $\%$ \\
\hline \multicolumn{17}{|l|}{ Leisure Activity } \\
\hline Radio & 10 & 50 & 19 & 44 & 4 & 20 & 8 & 19 & 0 & 0 & 2 & 5 & 6 & 30 & 10 & 23 \\
\hline Television & 18 & 90 & 37 & 86 & 1 & 5 & 3 & 7 & 0 & 0 & 1 & 3 & 1 & 5 & 0 & 0 \\
\hline Hobbies & 7 & 35 & 6 & 14 & 3 & 15 & 5 & 12 & 0 & 0 & 2 & 5 & 6 & 30 & 8 & 19 \\
\hline Sit and Think & 10 & 50 & 17 & 40 & 0 & 0 & 4 & 9 & 0 & 0 & 0 & 0 & 10 & 50 & 18 & 42 \\
\hline Letters & 1 & 5 & 3 & 7 & 4 & 20 & 9 & 21 & 5 & 25 & 7 & 16 & 7 & 45 & 21 & 49 \\
\hline Walk or Ride & 3 & 15 & 15 & 35 & 5 & 25 & 14 & 3.3 & 2 & 10 & 3 & 7 & 10 & 50 & 7 & 16 \\
\hline Library & 0 & 0 & 1 & 2 & 0 & 0 & 1 & 2 & 1 & 5 & 1 & 2 & 19 & 95 & 38 & 88 \\
\hline Movies & 0 & 0 & 0 & 0 & 0 & 0 & 0 & 0 & 0 & 0 & 2 & 5 & 20 & 100 & 41 & 95 \\
\hline Visit Friends & 4 & 20 & 2 & 5 & 5 & 25 & 28 & 65 & 4 & 20 & 9 & 21 & 7 & 35 & 4 & 9 \\
\hline Religious Activities & 0 & 0 & 0 & 0 & 2 & 10 & 14 & 33 & 0 & 0 & 1 & 2 & 18 & 90 & 25 & 58 \\
\hline Club Meeting & 0 & 0 & 0 & 0 & 2 & 10 & 3 & 7 & 2 & 10 & 8 & 19 & 16 & 80 & 28 & 65 \\
\hline Play Cards & 0 & 0 & 2 & 5 & 2 & 10 & 11 & 26 & 4 & 20 & 4 & 9 & 14 & 70 & 23 & 53 \\
\hline
\end{tabular}




\section{Vocational Adjustment}

The major occupation in the past lives of the respondents did not vary markedly from one group to the other. The major occupations in both groups were in the semi-skilled and skilled area, and homemaking. Only one person in the study group now worked occasionally for pay. Nine members of the control group worked for pay. Three worked full time, three part time, and three worked only occasionally. Neither group indicated much interest in full time or part time employment. Ninety-five per cent of the study group and $81.3 \%$ of the control group said they were disinterested in full time employment. The proportions disinterested in part time employment were, S-85\%, C-62.8\%.

The larger percentage of the study group expressing disinterest in employment may partially be due to the fact the study group contained a larger proportion of women than the control group and cannot be attributed to medical differences alone.

The figures correlate well with those from the question, "Have you looked for employment in the past year?" Both groups gave a high percentage of "no" answers, S-95\%, C-93\%. Of the 17 study group members who said they were not interested in employment, health was given as the reason in $71 \%$ of the cases, compared to $56 \%$ of the 27 control group members who indicated health was 
their reason for being disinterested in employment.

\section{Finances}

The mean monthly income for the study group was $\$ 259.95$ and $\$ 304.02$ for the control group. A test and chi square test run on the income figures indicated that the two income groups came from the same population at the .05 level of significance, $\left(t=.96, d_{.} f_{.}=60 ; \mathrm{chi}^{2}=.6275 ; \mathrm{d} . \mathrm{f}_{0}=1\right)$. The monthly income range of the study group was $\$ 130.00$ to $\$ 496.00$ with a median income of $\$ 320.00$. The income range of the control group was $\$ 84.00$ to $\$ 844.00$ with a median income of $\$ 350.00$ per month, a negatively skewed distribution.

The proportions of the EPP Project respondents in the various levels of monthly income varied considerably from the proportions found in the N. Y. Study population as seen in Table IV. Slightly over $52 \%$ of the EPP Project population had an income of $\$ 300.00$ per month or more. Only seven per cent of the N. Y. Study population reported a monthly income figure this high. Conversely, $69 \%$ of the N. Y. Study sample had an income of less than $\$ 200.00$ per month, and only $27 \%$ of the EPP Project sample reported a monthly income below $\$ 200.00$.

A difference was also noted in the sources of income between the EPP Project and the N. Y. Study. In the N. Y. Study $23 \%$ of 
TABLE IV

A VERAGE MONTHLY INCOME OF PATLENTS INTERVIEWED

\begin{tabular}{lcc}
\hline & $\begin{array}{c}\text { EPP Project } \\
\text { Percent } \\
(\mathrm{N}=63)\end{array}$ & $\begin{array}{c}\text { N. Y. Study } \\
\text { Percent }\end{array}$ \\
\hline Under $\$ 50$ & 0 & $(\mathrm{~N}=167)$ \\
$50-99$ & 1.6 & 22 \\
$100-199$ & 25.4 & 43 \\
$200-299$ & 12.5 & 13 \\
$300-399$ & 23.9 & 5 \\
400 and over & 28.6 & 2 \\
Don't know & 0 & 10 \\
No answer & 8.0 & $100 \%$ \\
\hline
\end{tabular}

the respondents were receiving funds from the department of welfare, and $26 \%$ from other relatives. In the EPP Project only $1.6 \%$ of the sample were receiving funds from welfare, and only $4.4 \%$ were getting money from other relatives. Much larger proportions of the EPP Project sample than the ${ }^{\circ} N$. Y. Study sample received income from private savings or investment, EPP-36.5\%, N. Y.$12 \%$, and from Social Security, EPP-90.5\%, N. Y. $-57 \%$. It was also noted the number of income sources per individual was higher 
in the EPP Project sample than in the N. Y. Study, indicating that the EPP Project sample was more financially stable due to its higher income level and its broadex income base.

TABLE V

NUMBER OF INCOME SOURCES

$\begin{array}{cc}\text { EPP Project } & \text { N. Y. Study } \\ \text { Percent } & \text { Percent } \\ (\mathrm{N}=63) & (\mathrm{N}=167)\end{array}$

Single Source

14.3

42

Two Sources

49.2

46

Three Sources

33.3

11

Four Sources

3.2

1

$100 \%$

$100 \%$

The factors of higher monthly income, more financial independence, and a broader individual income base all show that the general financial status of the EPP Project sample was substantially better than that of the N. Y. Study sample.

In the EPP Project data a significant difference was noted between study group and control group answers to the question "Are you having any difficulty managing on your income?" Thirty-five per cent of the study group and $18.6 \%$ of the control group answered 
yes, $\mathrm{chi}^{2}=12.07$, d.f. $=1, \mathrm{p} .<.05$

Of the $35 \%$ of the study group who indicated they were having difficulty managing on their incomes, nearly half lis ted medical expenses as the area where they had the most difficulty budgeting funds. This compares with about $12 \%$ of those having difficulty in the control group who mentioned medical expenses as the area giving them the most difficulty. Medical care, dental care and prosthetics were lis ted more of ten by the study group than the control group as.items they delayed purchasing because they could not afford them.

It should be noted that a substantial majority of both groups reported they were not having difficulty managing on their incomes, $\mathrm{S}-65 \%, \mathrm{C}-81.4 \%$.

\section{Adjustment to Illness}

There was no significant difference between the two groups in their incidence of being housebound due to illness in the past year. Over half of the total sample said they had not been hous ebound for more than a one day period due to illness, S-55\%, C-58.2\%. Fortyfive per cent of the study group and $25.5 \%$ of the control group reported that they had been readmitted to a hospital since the time of the Kaiser Study. A chi square test was run on these figures and showed there was a difference between the two groups at the $.05 \%$ 
level of significance $\left(\mathrm{chi}^{2}=9.50, \mathrm{~d}_{.} \mathrm{f}_{\mathrm{f}}=1\right)$. Only two of the 27 readmissions were admitted to a hospital other than Kaiser.

The figures would indicate that there was a substantial difference between the two groups in their need for treatment after hos pitalization. Doctors had prescribed follow up treatment for $75 \%$ of the study group and $60.4 \%$ of the control group.

TABLE VI

KINDS OF TREA TMENT PRESCRIBED

\begin{tabular}{lcccc}
\hline & \multicolumn{2}{c}{ Study } & \multicolumn{2}{c}{ Control } \\
& Frequency & $\begin{array}{l}\text { Percent } \\
(\mathrm{N}=20)\end{array}$ & Frequency & $\begin{array}{l}\text { Percent } \\
(\mathrm{N}=43)\end{array}$ \\
\hline Diet & 4 & 20 & 12 & 27.9 \\
Exercise & 4 & 20 & 4 & 9.3 \\
Medication & 13 & 65 & 21 & 48.8 \\
Rest & 5 & 25 & 8 & 18.6 \\
Dressings & 0 & 0 & 1 & 2.3 \\
Other & 2 & 10 & 3 & 6.9 \\
\hline
\end{tabular}

It was found that a larger proportion of the study group than the control group was taking medicine prescribed by a doctor, S-7.0\%, C-62.8\%. However, relatively more of the control group 
than the study group were taking medicines not prescribed by a doctor, $\mathrm{S}-25 \%, \mathrm{C}-44.2 \%$. It also appeared from the data that the study group spent substantially more on medicine than the control group.

TABLE VII

MONTHLY AMOUNT SPENT ON MEDICINE

\begin{tabular}{lcccc}
\hline & \multicolumn{2}{c}{ Study } & \multicolumn{2}{c}{ Control } \\
& 6 & 30 & Frequency & $\begin{array}{c}\text { Percent } \\
\text { (N }=43)\end{array}$ \\
\hline$\$ 0-5$ & 5 & 25 & 26 & 61 \\
$6-10$ & 2 & 10 & 7 & 16 \\
$11-15$ & 2 & 10 & 3 & 7 \\
$16-20$ & 2 & 10 & 4 & 9 \\
20 and over & 3 & 15 & 3 & 7 \\
Not Ascertainable & 3 & $100 \%$ & 43 & $100 \%$ \\
\hline
\end{tabular}

By ins pection it did not appear there was any significant difference between the groups with regard to the proportion attending a clinic. Over $60 \%$ of both groups were attending the Kaiser Clinic. No respondent reported he was attending a clinic other than Kaiser. It was more frequently a problem in the study group to get to the 
clinic than in the control group, S-44\%, C-17\%. The time consuming length of the trip to the clinic seemed to be the principal factor which made the clinic visit inconvenient in both groups.

In over half the cases in both groups the illness which hospitalized the respondent at the Kaiser Foundation Hospital between March and June 1965 had begun from one to five years prior to his hospitalization, S-55\%, C-60.4\%. Proportionately more of the study group members than control group members felt their illness had changed their daily lives, $\mathrm{S}-65 \%, \mathrm{C}-51 \%$. In both groups there was a higher frequency of physical impairment than mental or emotional impairment, though the latter two were hard to assess. The study group had a much higher proportion of physical impairment limiting self care than the control group, $\mathrm{S}-70 \%, \mathrm{C}-49 \%$. The effects of this impairment could be seen in the higher proportion of the study group which never did their own shopping, S-30\%, C-14\%; required help at night, S-25\%, C-21\%; or needed a mechanical aid in walking or moving about, S-30\%, C-11\%.

It should be noted that the two samples in the EPP Project were drawn from the same general discharge population of the Kaiser Foundation Hospital. The two groups were similar in the area of finances and in their general demographic characteristics with the exception of sex composition. Differences noted between the two groups in their attitudes toward employment, leisure 
activities, and in the degree of their physical impairment seemed to confirm the doctors' predictions that the study group would have more needs after leaving the hos pital.

Further comparisons will be dealt with in the next chapter and findings related to the research hypotheses. 
CHAPTER V

\section{FINDINGS: INFERENTIAL}

This chapter deals with the inferences based on the findings of the EPP Project. These inferences were made by considering the five areas of need in relation to the four research hypotheses.

The five areas of need were (1) living arrangements, (2) use of leisure time, (3) vocational adjustment, (4) finances, (5) adjustment to illness.

The four research hypotheses were:

1. That those who were adjudged by the doctors as having more medical needs (study group) also have more social needs .

2. That the medical and social needs of the study group are the same as the medical and social needs of the control group.

3. That the medical needs at the time of discharge are the same as the medical needs approximately one year and four months after discharge.

4. That the medical and social needs of the control and study group are the same as those determined in the N. Y. Study. 
A central consideration was the testing of the Greenlick formula (10) for determining post-hospital needs. The first hypothesis tests whether there might be a hidden set of social factors in the medical needs as predicted by doctors, and also throws light on the need for social workers, whose role is psychosocial as well as medical.

The second hypothesis further tests the above factors and centrally tests whether the predictions of the doctors held up empirically. The hypothesis was put in a null form at this stage in order to be more consistent with sub-hypotheses for reporting purposes.

As some time had elapsed since the doctors' predictions, there was the possibility that (1) the data might be inappropriate and (2) that predictions based upon immediate post-hospital needs might not reflect subsequent improvement or deterioration. The third hypothesis would indicate whether temporal factors should be included in the prediction formula, whether in fact the doctors were able to designate relative needs by classes, duration of need for social workers, and the directions of changes in needs.

The fourth hypothesis tested the generality of the prediction formula in indicating what factors might be present in post-hospital patients of possibly different socio-economic status. Medical needs after discharge might be affected by factors not intrinsic to the 
medical conditions themselves. This hypothesis might lead to a more general theory or might indicate the extent to which independent studies were indicative in assessing patient needs and need for social workers.

Because of uncontrolled factors, it was considered desirable to approach both inferential and descriptive aspects from several points of view. Findings could be considered better validated to the degree that they were consistent and convergent.

\section{Hypothes is I}

The first hypothesis considered in the EPP Project assumed for test reasons that there was no difference in the extent of the medical and social needs in the study group. Here, hypotheses I and II can be treated together and were approached with the null hypotheses:

There is no difference between the study and control groups with respect to:

$$
\begin{array}{cl}
\mathrm{H}_{\mathrm{O}} 25 \mathrm{a}^{1} \text {, need for a person to do hous ework } & \begin{array}{l}
\text { difference } \\
\text { (more in } \\
\mathrm{Chi}^{2}=13.8, \mathrm{~d} . \mathrm{f} .=1, \mathrm{p} .<.05
\end{array} \\
\mathrm{H}_{\mathrm{O}} 29 \mathrm{a}, \text { patient working for pay } & \begin{array}{l}
\text { difference } \\
\text { (more in con }
\end{array} \\
\mathrm{Chi}^{2}=29.6, \mathrm{~d} . \mathrm{f} .=1, \mathrm{p} .<.05 & \begin{array}{l}
\text { trol group) } \\
\text { troup }
\end{array}
\end{array}
$$

1 The post subscript refers to the item number on the schedule. 
$\mathrm{H}_{\mathrm{o}} 35$, mean monthly income

$t=2.00, d_{.} .=60, p_{.}>.05 \quad$ no difference

$\mathrm{Chi}^{2}$ med. $=.6275$, d.f. $=1$, p. $>.05$ no difference

$\mathrm{H}_{\mathrm{O}}$ 39a, difficulties in managing on income difference

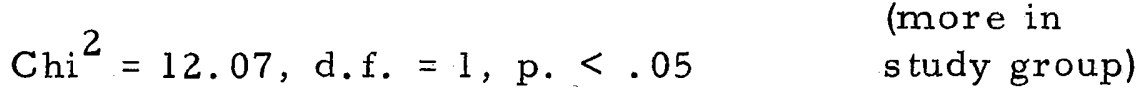

$\mathrm{H}$ 40b, delay in purchasing needs difference

$$
\mathrm{Chi}^{2}=28.70, \text { d.f. }=1, \mathrm{p} .<.05 \quad \begin{aligned}
& \text { (more in } \\
& \text { study group) }
\end{aligned}
$$

$\mathrm{H}_{\mathrm{O}} 39 \mathrm{c}$, amount of contributions to church difference (more in conand organizations trol group) $t=16.48$, d.f. $=40$, p. $<.05$

It was observed that a greater proportion of the study group than the control group attended the clinic for routine checkups, $\mathrm{S}-20 \%, \mathrm{C}-14 \%$. The opposite was observed as it related to their attendance at the clinic for specific complaints, S-40\%, C-53.4\%. Items 50c and 50d of the schedule asked whether going to the clinic was a problem and whether it was convenient to go to the clinic from the place of residence. Responses of the study group indicated these patients had more difficulty in getting to the clinic.

$\mathrm{H}_{\mathrm{O}} 43 \mathrm{a}$, has the doctor prescribed treatment

$$
\mathrm{Chi}^{2}=7.32, \text { d.f. }=1, \mathrm{p} .<.01
$$

significant difference, with more in study group 
With respect to $\mathrm{H}_{0} 43 \mathrm{~b}$, types of treatment prescribed, the following table indicates the differences noted.

TABLE VIII

TYPES OF TREA TMENT PRESCRIBED

\begin{tabular}{lccc}
\hline & \multicolumn{2}{c}{ Percentages } & $\begin{array}{c}\text { Significantly } \\
\text { Higher } \\
\text { Group }\end{array}$ \\
\hline Diet & $20 \%$ & Control & Control \\
Exercise & $20 \%$ & $28 \%$ & Study \\
Medicine & $65 \%$ & $9.30 \%$ & Study \\
Rest & $25 \%$ & $49 \%$ & Study \\
Dressings & $0 \%$ & $18.6 \%$ & $-.32 \%$ \\
Other & $10 \%$ & & $-7 \%$ \\
\hline
\end{tabular}

$\mathrm{H}_{\mathrm{O}} 43 \mathrm{e}$, taking prescribed medication

It was found that a larger proportion of the study group was taking medications prescribed by a doctor, S-70\%, C-62.8\%.

$\mathrm{H}_{\mathrm{O}} 45 \mathrm{a}$, amount spent on medications

Twice as many in the study group as in the control group spent over $\$ 16.00$ per month. Twenty-seven per cent of the study group compared to $64 \%$ of the control group spent under $\$ 6.00$ per 
month for medications.

$\mathrm{H}_{\mathrm{O}} 45 \mathrm{~b}$, problem in buying medications

$90 \%$ of control group never, to $63 \%$ of study group

$\mathrm{H}_{\mathrm{O}} 42 \mathrm{a}$, hospital readmissions

$$
\mathrm{Chi}^{2}=9.50, \text { d.f. }=1, \text { p. }<.05
$$

significant difference with more in study group

$\mathrm{H}_{\mathrm{O}} 41$, housebound for more than one day no significant $\mathrm{S}-45 \%, \mathrm{C}-41.8 \%$ difference shown

$\mathrm{H}_{\mathrm{o}} 57 \mathrm{a}$, problem with sleeping

difference $\mathrm{S}-25 \%, \mathrm{C}-37 \%$ greater for control group

$\mathrm{H}_{\mathrm{O}} 60$, bed status

Ten per cent of the study group as opposed to $0 \%$ in control spent most of their time in bed.

$\mathrm{H}_{\mathrm{O}} 64$, walking $\mathrm{s}$ tatus

By observation, $30 \%$ of the study group and only $12 \%$ of the control group needed help with ambulation.

$\mathrm{H}_{\mathrm{O}} 66 \mathrm{a}$, present need for a visiting nurse Evidence favored little need for services of a visiting nurse. Five per cent of the study group was using the services of the visiting nurse. No one in the control group was using this service. 
The fact that the study group felt more need for help and had used more help than the control group after leaving the hospital supported the hypothesis that the study group had more extensive medical-social needs than the control group.

As pointed out in the previous chapter, the leisure time of both groups tended toward sedentary activity in the home. This fact would be significant in planning leisure time activity for older persons. The lack of transportation might have been one factor in the high proportion of leisure time activities centered in the home. Differences were in the direction of confirming the predictions of need on a medical basis, and the priority of medical factors in the study group.

In the study group $30 \%$ needed some help with ambulation. The study group appeared to be more confined as a result of more intense medical need. This was indicated by the fact that $90 \%$ of the study group seldom or never participated in religious activity as compared with the control group where only $58 \%$ seldom or never participated. Another factor which supported this inference was that $35 \%$ of the study group as compared with nine per cent of the control group seldom or never visited friends. These findings 
support the inference that social activity outside of the home was limited by medical factors.

As pointed out in the previous chapter, the $71 \%$ of the study group who said they were not interested in employment gave health as the reason for their being disinterested. This indicated a close relationship between medical needs and social needs in terms of vocational adjustment.

In the area of finances $35 \%$ of the study group indicated they had difficulty in managing on their incomes. Nearly half lis ted medical expense as the area where they experienced the most difficulty in budgeting their funds.

Twenty per cent of the study group indicated they delayed purchasing medical care or prosthetics because they could not afford them. This high proportion of respondents having difficulty managing on their incomes and putting off needed purchases of medical care and prosthetics would point to a high proportion of unmet medical expense due to shortage of finances.

It was found there was little difference between the study group and the control group in relation to social needs. It was also found that in the area of medical need a significantly greater need was expressed by the study group than was expressed by the control group. The Kaiser Study predicted medical needs and a wide range of problems with few variables. The EPP Project, 
with evidence from different dimensions supported the Kaiser Study predictions.

\section{Hypothes is II}

The second hypothes is considered by the EPP Project as sumed that there was no difference between the medical and social needs of the study group and the medical and social needs of the control group.

The first factor considered was in the area of living arrangements. Twenty per cent of the study group indicated an expressed need for someone to come in and help with the housework while only ten per cent of the control group reported such a need. As shown in the previous chapter, twice the proportion in the study group as compared with the control group had used help since their release from the hospital and expressed a need for help at the time of the EPP Project. From this it could be inferred that the study group had more impairment than the control group. The demographic data indicated a close similarity between the two groups with the one exception that there was a higher proportion of women in the study group than in the control group. It would be expected that the incapacity of the woman would necessitate having someone to come in to help with the housework more often than if the male spouse were incapacitated. 
The findings indicated a significant difference between the two groups' use of leisure time in those activities which required going out of the home. That the study group was more impaired physically than the control group may have accounted for this difference.

A slightly higher proportion of the study group than the control group said they were disinterested in full time employment. A high proportion in both groups expressed disinterest in employment, but a significantly higher percentage of the study group attributed this to health reasons. From this data the inference was made that the two groups were different with respect to vocational adjustment. This was further evidence for rejection of $\mathrm{H}_{2}$.

The findings revealed no significant difference in the income of the two groups and this would support the hypothesis. It appeared also that both groups tended to reduce expressed desires to fit within their incomes.

However, the study group did express the feeling that buying medicine was a problem more often than the control group, S-38\%, C-10\%. From the fact that the study group found buying medicine and medical treatment more of a problem than the control group even with no significant difference in income, it could be inferred that the study group had more severe illness. The study group also had more medicine prescribed by doctors, S-65\%, C-48.8\%, which 
further substantiated the inference that the study group had more severe illness. It could also be inferred that there was a further reduction in purchases of expressed needs in the study group.

In spite of the fact the study group had more difficulty with transportation and ambulation, their patterns of attendance at the clinic were similar to those of the control group. This was further evidence to support the inference that the study group had more severe illness than the control group.

The tests described in the beginning of the chapter in the areas of living arrangements, use of leisure time, vocational adjustment and adjustment to illness indicated greater medical and social needs in the study group. This would lead to rejection of $\mathrm{H}_{2}$.

\section{Hypothes is III}

The third hypothesis considered by the EPP Project as sumed that there was no difference between the medical needs of the study group at the time of discharge and the medical needs of the study group approximately one year and four months after discharge.

Five dimensions of patient disability which appeared most likely to result in need for skilled nursing service after discharge were outlined by the panel physicians in the Kaiser Study. The dimensions were: (1) mobility, (2) continence, (3) need for rehabilitative services such as physical or occupational therapy, (4) 
mental state, particularly with regard to agitation, confusion, and coma, (5) need for special procedures or equipment. (Ten special needs were named as examples. They included parenteral medication, catheterization, irrigation of wounds, oxygen availability, etc.)

It was found in the EPP Project that ten per cent of this group were confined to their bed almost all of the time. Thirty-five per cent needed help with walking through the use of crutches or cane, wheelchairs or walkers, or the assistance of another person.

The area of continence was not analyzed because of the general nature of the responses, due in part to the lack of probing in the interview.

Twenty per cent of the study group said they needed help with exercise which had been prescribed by their doctors. It appeared that this need was not being met by aid from other members in the patients' households, nor were they going to the clinic to get this service. There was further evidence that this need was not being met by a visiting nurse.

Only two members of the study group showed evidence of impairment of their mental capabilities. One man's daughter had to provide some of the answers to the schedule, another could not be interviewed because of total mental impairment.

In the fifth area of need, that of special procedures or 
equipment, it was found that ten per cent of the study group required injections, etc. It was felt this hypothesis could not be proven conclusively because so many of the areas would require a diagnosis and the interviewers were not competent to make judgments regarding medical needs.

The Greenlick prediction formula was effective in ascertaining need for immediate post-hospital care but was less effective in predicting needs over time. The prediction formula could be modified to improve long-range prediction. While the five factors of mobility, continence, rehabilitation, mental s tate and special procedures or e $\overline{q u}$ ipmentent were good for predictive purposes, it was felt that the inclusion of a wider variety of less intensive factors would increase the precision of the measurement instrument. Even so, it was shown that the Greenlick prediction formula was valuable in determining statistically significant differences among discharged patients with respect to post-hospital needs, both immediately and over the period of time covered.

\section{Hypothesis IV}

The fourth hypothesis considered was that there was no difference in the needs of the control group and study group in the EPP Project and the needs determined in the N. Y. Study. The aim was to determine whether findings of this study 
would bear out ideas generally reported in social work literature and whether these findings corresponded to those of the N. Y. Study. Except where otherwise noted the control and study groups will be treated as one for purposes of comparison with the N. Y. Study, to make the EPP Project more comparable in treatment.

It was found that a higher proportion of the respondents in the EPP Project lived with a spouse. The EPP Project showed approximately $7.0 \%$ as opposed to only $41 \%$ of the respondents in the N. Y. Study who indicated they lived with a spouse.

It was observed that a comparable proportion in the N. Y. Study $(82 \%)$ and the EPP Project (S-95\%, C-81\%) voiced a disinterest in gainful employment. There seemed to be no significant difference in this area of vocational adjustment.

The EPP Project revealed that over $75 \%$ in both groups indicated satisfaction with their present living arrangements as compared with only $57 \%$ in the N. Y. Study. It was observed in Chapter IV that the respondents in the N. Y. Study were more needy. Twenty-three per cent of the N. Y. Study respondents received welfare as is tance as compared to only $1.6 \%$ in the EPP Project groups. This may indicate that the EPP respondents were better able to afford adequate housing than the respondents in the N. Y. Study.

In the N. Y. Study 32 or $14.5 \%$ of the respondents stated they 
had difficulty in the use of leisure time accompanied by some feeling of despair and hopelessness. In the EPP Project negligible, if any, need was shown in this area.

In the N. Y. Study $59 \%$ thought their illness was a big problem physically as opposed to $39.2 \%$ in the EPP Próject study group and $22.5 \%$ in the control group.

The N. Y. group had much more need for nursing care, medication, help with problems connected with their illnesses such as ambulation, prosthes is, night care, diet, and so on.

Demographic and social data in Chapter IV, as well as differences noted above, led to a clear rejection of the null hypothesis without the use of tests of significance. Differences in age-range, racial composition, class and economic status among other factors probably account for medical-social dissimilarities.

In the areas of living arrangements, leisure time, finances and adjustment to illness, little correlation was found between the respondents in the groups in the EPP Project and the respondents in the N. Y. Study. Rejection of the hypothesis came somewhat as a surprise, since social work literature tended to emphasize need, pathology and distress among the elderly.

One conclusion follows, that hospital and social work administrators cannot safely base expectations on general studies, since 
significant differences are found among the elderly in varying situations. More precise studies àre called for.

As compared with a general hospital population, the Kaiser group had much superior access to medical care with its social correlates. Their relative well-being points to what might be pos sible for other groups under a broader program of medical and income maintenance.

Related to this hypothesis there is evidence that elderly posthospital patients tend to have more than one problem and that difficulty in one area tends to precipitate difficulties in other areas. There seemed to be further need for identification of the special areas of social work service most needed by the elderly. The EPP Project and the N. Y. Study both seemed to reveal a need to know more about the strengths and assets that often accompany old age, as well as the problems.

There was indication of need to experiment with the social work techniques in order to find which ones are most successful in reaching the older client who is reluctant to seek out agencies or groups who would help him to meet his medical and social needs.

\section{Summary}

In the EPP Project, those who were designated as needing more medical care were found to have more social needs. After a 
lapse of time the doctors' predictions of differential needs held true. The Greenlick prediction formula was able to differentiate medical (and related social) needs among post-hospital dischargees. However, the formula might be improved with respect to both Type I and Type II errors and by taking into account the long run as well as the immediate post-discharge period. The population under study differed significantly from those in the N. Y. Study and, indeed, from general expectations in the social work literature. 


\section{CHAPTER VI}

\section{CONCLUSION}

This chapter will discuss general findings and values of the EPP Project, limitations, and suggestions for further research.

The discussion will focus on whether the medical needs of the elderly post-hospital patients as seen by the doctors at the time of discharge were the same as those seen approximately one and one half years later; whether the elderly post-hospital patients designated by the doctors as having more medical needs also had more social needs; and to what extent the meeting of such needs might warrant the services of a social worker on the hospital staff.

\section{Summary of Major Findings}

The EPP Project pointed up that the surviving elderly hospital dischargee was not necessarily on a course of deterioration. The 20 elderly hospital discharge patients in the special study group had been adjudged by their doctors to have a high probability of need for some form of post-hospital care. These patients all had one or more areas of disability which would warrant prediction of posthospital nursing care need. Approximately one and one half years after discharge, the EPP Project found only one of these patients in a nursing home and none using skilled nursing care in their own 
homes. Forty-five per cent of them were doing their own housework and only 20 per cent felt the need for housework help from outside the hous ehold.

It was not found that there was a significant difference in the social needs of the two groups. There was no significant difference found in the incomes of the study group as opposed to the control group. The median income of the study group, $\$ 320$, and of the control group, $\$ 350$, cannot be regarded as typical of elderly people in other areas. The N. Y. Study population contained only seven per cent with incomes at the $\$ 300$ per month level or higher. The proportion of the study group residing in their own homes was not significantly different from the control group. Both groups had a similar proportion residing with spouses. The groups did vary with regard to cost of medicine with the study group's expenditure for medicine exceeding that of the control group. This higher expenditure coupled with a somewhat lower income resulted in the study group experiencing more difficulty in financial management.

A survey of the kind of help needed did not indicate that this group of elderly post-hospital patients needed the services of a medical social worker, with few exceptions, after release. The study indicated a lower level of patients' needs in kind and extent than social workers' expectations might suggest. A lack of active participation in the community around them was found to be a 
pattern in both groups. Community organization more than casework service, volunteer aid more than professional help, were the areas most needing expansion.

\section{Values of the Study}

It was expected that the EPP Project would show that dis charged elderly patients were in significant need of social workers.' services in making an adjustment to illness and in obtaining services from other agencies and individuals. However, the study did not substantiate this need. In most areas the patient or his relatives were meeting the need. Those areas in which the elderly discharged patient had not had his needs met lay, for the most part, in the realm of volunteer services, e.g., obtaining transportation, groceries, library books, etc. These findings indicated a direction for better allocation of the workload of the hospital social worker and the use of differential levels of social service personnel.

The EPP population did not indicate a need for a social worker's intervention with other agencies, with obtaining employment, or with improving living conditions. Social work services were needed in budgeting to cover cost of expensive medicine and in locating and utilizing community resources for dental care, dentures, glasses and other prosthetic devices.

The respondents were found to have difficulty in getting to the 
clinic and in doing their shopping. Lack of transportation and lack of stamina for these time-consuming errands pointed to the need for volunteer services. It was further inferred that lack of transportation contributed to the minimal involvement in church affairs and other activities outside the home. Thus, volunteer efforts would enrich the social life of the elderly patients, also.

Less than one-third of the respondents were involved in religious activities. The study showed a marked tendency toward sedentary life among the elderly post-hospital patients. There was much emphasis on television, radio, sitting and thinking to occupy leisure time when more active participation in community events might give them a more satisfying life.

Most people in both groups lived in their own home and only one in each group was living in a congregate care situation. Seventy per cent of the special study group and $72 \%$ of the control group were living with their spouses while those living alone comprised $15 \%$ and $14 \%$ respectively. This was in contrast to the N. Y. Study where only $41 \%$ of those interviewed were living with a spouse. Among the EPP respondents there was a high degree of satisfaction with living arrangements. Those who did not have a spouse in the home had friends or relatives in the community on whom they could call.

The EPP Project showed that those in the study group had 
more need for someone to come in to help with housework than did the control group. It might have been.inferred that this was due to poor health. However, the fact that $70 \%$ of the study group was female as opposed to only $35 \%$ of the control group might have biased these results. Men's spouses are traditionally more apt to undertake the housework than are women's spouses. Of those respondents using outside help, all indicated the need was for hous ekeeping help to the exclusion of nursing help. This would indicate that the efforts of the community should be less on provision for home nursing service and more on establishing a homemakers: ${ }^{1}$ register to provide low-cost housekeeping help to the elderly when needed.

The study group more frequently indicated difficulty in managing on their income than did the control group. Related to this, they also reported spending more on medicine than the control group did. There was evidence that the majority of both groups had retreated to living within their income by reducing their wants. The EPP Project revealed that there were people even within the lower middle class experiencing difficulties with special needs such as obtaining medicine or pros thetics, the cost of which was excessive in relationship to income. The study suggested an obligation on the social work profession to look at individual variations and needs. Programs designed for categories overlook these 
dissimilarities. An emphasis on casework was needed on an individual basis, but a greater need was for organization of services. A community-based social worker, rather than hospitalbased, was indicated.

\section{$\underline{\text { Critique }}$}

A number of difficulties common to this type of study were encountered. While attempts were made to eliminate these points by pretesting and by sharing interview experience in subsequent discussions among project members, in the final analysis it turned out that additional revisions would have enhanced utility of the schedule.

The schedule was patterned after the one used in the N. Y. Study and the questions were largely borrowed directly from the N. Y. Study in order to facilitate comparisons and make findings more general. Experience of project members in administering the schedule and tabulating responses indicated that for the EPP Project purposes modifications were needed in numbering, phrasing and positioning of some questions.

Questions were numbered from one to 69 , but 29 of those questions were comprised of two to six separate parts. The subquestions were designated by letters $A$ to $F$. This added 56 supplementary responses making a total of 125 , most with a number 
of sub-categories. This contributed to confusion in tabulating responses and provided opportunity for error particularly since the answers were tallied by code. Eliminating all lettered subdivisions and assigning each question a number would have accelerated the tabulating task and reduced rechecking for error. Adding an additional code for "no response" would have fur ther reduced rechecking because of insufficient number of responses. Some questions were ambiguous and open to various interpretations not only among the respondents but also arnong the interviewers. Some questions were time consuming to adminis ter yet elicited no manageable information. Other questions did not elicit enough information for adequate analysis. Questions which should have been in sequence for maximum continuity of thought were, in some instances, separated by unrelated questions.

Several questions have been singled out as examples of unsatisfactory approach to information desired. "Would you like to work?" was intended to explore the need for help in obtaining employment. Many respondents answered in the affirmative, then added that their physical condition precluded employment.

Another question, "Who is the head of the hous ehold?" had no value. In all instances where patients were living with spouses the answer designated the husband as the household head. This was culturally ideal but not reality in an unknown number of cases. 
Questions regarding sources and amounts of income in the household were confusing and vague. Answers sometimes included total income of other relatives in the hous ehold, e.g., employed sons and siblings, while others included only that portion of relatives' income made available to the respondents' control.

That section of the schedule requesting itemization of food eaten for the past three meals placed a burden on the memory of the elderly post-hospital patients and garnered a bulk of information which was unmanageable for the purposes of this study.

Three related questions probed the shopping habits of the population by asking how often they shopped for food and whether at chain stores, neighborhoodstores, or other. This did not take into account that for many the neighborhood store was a chain store, not an independently owned store as the question intended. Also, frequency of shopping trips was influenced more by proximity to a store than by household organization.

Another question searched the reason why those who indicated a need for outside help with hous ework did not use outside help. The coded reas ons listed on the schedule were: (1) Didn't need, (2) No one available, (3) Didn't like to ask and (4) Other. A fifth and very important response that should have been included was: (5) Couldn't afford it.

A $70 \%$ negative response was obtained to the question, "Does 
anyone else in your house get up at night to help you ?" More affir mative answers might have been given if the phrase "when you need it" had been added to make the question more explicit.

Many of the modifications necessary to improve the schedule would have been recognized in advance if pretesting had been more extensive and, more important, if tallying of information gathered in pre-tests had been attempted.

A stronger test of predictive power of the Greenlick formula would have taken into consideration differential death rates, but rates for those having moved out of the area were not available. The two samples, never theless, should not have excluded deceased persons.

\section{Suggestions for Further Research}

The EPP Project was a study in one point of time on a population of elderly people who were members of the same group health insurance program, the Kaiser Foundation Health Plan. Is this population unique or would studies on a different population of elderly hospital dischargees, e.g., one covered only by Medicare, validate the findings of the EPP study?

A study on another age group, such as the 55 to 65 age bracket, would allow comparisons to determine whether the over 65 group is dissimilar and requiring of special consideration. What 
happens to those who survive to 85 years or more? It might be anticipated that the latter as a group would be spending more on medicine and outside help with nursing needs or household management. It would be expected that fewer would be living in their own homes or with spouses. A study should be under taken to explore these and other characteristics of the 85 and over group.

The study group, as it turned out, contained a larger proportion of females than the control group. The questions arise whether this occurred by chance, whether females might in general show a greater post-release need, whether male mortality is greater, or whether other factors are operative.

A future study might be undertaken to a nalyze more carefully the relationship of family income to community participation. Do we find different medical characteristics and social characteristics in the rural population, isolated from intensive medical care facilities? Does transportation pose even greater obstacles for them in the health and social areas? How can we bring services to the localities or bring the elderly to the medical and social centers?

While reduced incomes and poor health had curtailed activities and changed living patterns of the EPP population, the interviewers found them to be far different from the stereotyped notion of the elderly retired person, rocking on his porch, lost in memory 
of better days, bitter and complaining of present status, with nothing to look forward to but death.

These people were cordial and hospitable, proud of their homes and families, voicing few complaints over the economic turn of events which placed them in the position of paying today's inflationary prices with savings or pensions earned during other years. They were relatively free of suspicion and hostility-the traits so often attributed to them.

In contrast to the weariness and disinterest which many of the interviewers had observed when working with welfare recipients, these retired people had sufficient money for basic necessities to free their energies for enjoyment of their leisure. They were interested in their fellow men and in world developments.

As a greater proportion of our population moves into the retired age bracket, as welfare and pension benefits move toward closer relationship to the price index, the research group concluded, more opportunity must be afforded the elderly to maximize the satisfactions and comforts which an affluent society now provides for the working population. 


\section{BIBLIOGRA PHY}

1. Anderson, David L. Hospital discharge of the geriatric patient: a team process. Journal of the American Geriatrics Society 3:266-277. 1963.

2. Birren, James E. (ed.). Handbook on aging and the individual. Chicago, University of Chicago Press, 1959. 939 p.

3. Blenkner, Margaret, Julius Jahn and Edna Wasser. Serving the aged, an experiment in social work and public health nursing. New York, Community Service Society of New York, 1964. $249 \mathrm{p}$.

4. Boehm, Werner $W$. The plan for the social work curriculum study. Council of Social Work Education, Aug., 1956. Document 6-70-12. $103 \mathrm{p}$.

5. Butts, Sarah A. Casework services in public assistance medical care. Washington, Department of Health, Education and Welfare, 1962. $110 \mathrm{p}$.

6. Collins, Joan. The social work content of general medical services. In: Problems and progress in medical care, ed. by George McLachlan, New York, Oxford University Press, 1964. p. 135-169.

7. Elconin, Ann F., Roger Egeberg and Olive Dunn. An organized hospital home care program. American Journal of Public Health 54:1106-1117. 1964.

8. Goldmann, Franz. What are social workers in general hospitals doing for long-term patients? Social Work 5:6877. 1960.

9. Gordon, Gerald. Role theory and illness; a sociological perspective. New Haven, College and Univérsity Press, 1966. $158 \mathrm{p}$.

10. Greenlick, Merwyn R., Arnold V. Hurtado and Ernest W. Saward. The objective measurement of the post-hospital needs of a known population. American Journal of Public Health 56:1193-1198. 1966. 
11. Heyman, Margaret M. Effective utilization of social workers in a hospital setting. Chicago, American Hospital Association, 1961. $160 \mathrm{p}$.

12. Hollis, Florence. Casework: a psychosocial therapy. New York, Random House, 1965.300 p.

13. Kent, Donald P. Aging and government policy: outlook for progress in the 1960's. In: Aging and the economy, ed. by Harold Orbach and Clark Tibbetts, Ann Arbor, University of Michigan Press, 1963. p. 195-208.

14. Kurtz, Russell H. (ed.). The encyclopedia of social work. New York, National Association of Social Workers, 1960. $767 \mathrm{p}$.

15. Leeds, Morton. The aged, the social worker, and the community. Cleveland, Howard Allen, 1961. 114 p.

16. Mehling, Grace M. Discharge planning for chronically ill veterans. Social Work 8:79-85. 1961.

17. Rosin, Arnold J. and Dierdre D. Eddison. Geriatric patients out of hospital: a clinical and social study. Medical Care $23: 145-150.1964$.

18. Schwartz, Doris, Barbara Henley and LeonardZeitz. The elderly ambulatory patient: nursing and psychosocial needs. New York, Macmillan, 1964. 356 p.

19. Shanas, Ethel. The health of older people; a social survey. Cambridge, Harvard University Press, 1962. 250 p.

20. Steinberg, Franz U. and Thelma Frost. Geriatric rehabilitation in a general hospital. Geriatrics 18:158-164. 1963.

21. Total care moves into the home. Medical World News 6:63-65. 1965.

22. Travis, Georgia. Chronic disease and disability; a basic medical-social guide. Berkeley, University of California Press, 1961. 295 p. 
23. Ullman, Alice and Gene G. Kassebaum. Referrals and services in a medical social work department. Social Service Review 35:261-262. 1961 .

24. U. S. Bureau of the Census. Current Population Reports . Illustrative projections of states; 1970 to 1985. Washington, D. C., ser. P-25, No. 326. 1965. 106 p.

25. U. S. Congress. Senate. Special Committee on Aging. Eighteen months of experience with the medical assistance for the aged (Kerr-Mills) program: a report. 87 th Congress, 2nd session. 1962. $90 \mathrm{p}$.

26. U. S. Dept. of Health, Education and Welfare. A brief explanation of "medicare," health insurance for people 65 or older. 1965. 11 p. $(0-793-699)$

27. U.S. Dept. of Health, Education and Welfare. Public Health Service. Heal th S tatistics from the U.S. National Health Survey. Hospitalization: patients discharged from shortstay hospitals, U. S., July 1957 - June 1958. ser. B-7. Dec., 1958. $40 \mathrm{p}$.

28. Persons receiving care at home, U.S. July 1958 - June 1959. ser. B-28. Oct., 1961. 30 p.

29. U.S. Dept. of Health, Education and Welfare. Report of the White House Conference on Aging. The nation and its older people. April, 1961. 333 p. 